\title{
Joining of Silicon Nitrides Using Oxynitride Glasses
}

\author{
Michael H. O'Brien
}

Published March 1993

\section{Idaho National Engineering Laboratory \\ EG\&G Idaho, Inc. Idaho Falls, Idaho 83415}

Prepared for the

U.S. Department of Interior, Bureau of Mines and for the

U.S. Department of Energy Under DOE Idaho Operations Office

Contract DE-AC07-76ID01570 


\begin{abstract}
This report presents a study conducted for the U. S. Department of the Interior's Bureau of Mines on commercial silicon nitrides that were successfully joined using oxynitride glasses. Sintered silicon nitride was joined by either closed or glass-filled joints. Glass-filled joints were successfully used on hot-pressed silicon nitrides and were comparable in fast fracture strength to the unjoined silicon nitrides up to approximately $1000^{\circ} \mathrm{C}$. Above that temperature, strengths decreased rapidly and glass flow failure began. The study observed that time-dependent failure currently limits the service temperatures of glass-filled joints. Creep failure occurred in excess of $1000^{\circ} \mathrm{C}$. Between 900 and $1000^{\circ} \mathrm{C}$, slow crack growth failure was observed. Cavitation (or viscous deformation) was the rate-controlling mechanism of slow crack growth.
\end{abstract}




\section{CONTENTS}

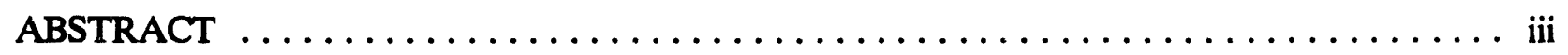

INTRODUCTION $\ldots \ldots \ldots \ldots \ldots \ldots \ldots \ldots \ldots \ldots \ldots \ldots \ldots \ldots \ldots \ldots \ldots \ldots$

BACKGROUND $\ldots \ldots \ldots \ldots \ldots \ldots \ldots \ldots \ldots \ldots \ldots \ldots \ldots \ldots \ldots \ldots \ldots$

PHASE EQUILIBRIA OF THE Y-Si-Al-O-N SYSTEM $\ldots \ldots \ldots \ldots \ldots \ldots \ldots \ldots \ldots \ldots$

EXPERIMENTAL PROCEDURES $\ldots \ldots \ldots \ldots \ldots \ldots \ldots \ldots \ldots \ldots \ldots \ldots \ldots$

Glass-Making Procedures $\ldots \ldots \ldots \ldots \ldots \ldots \ldots \ldots \ldots \ldots \ldots \ldots \ldots \ldots \ldots \ldots$

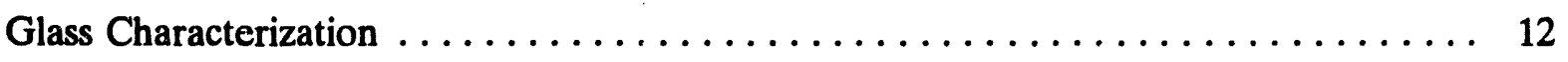

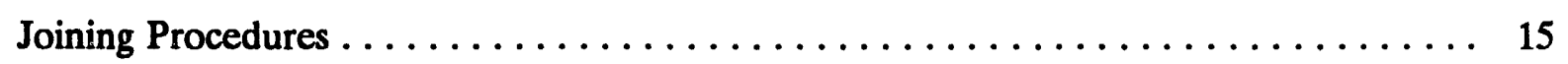

Joint Characterization $\ldots \ldots \ldots \ldots \ldots \ldots \ldots \ldots \ldots \ldots \ldots \ldots \ldots \ldots \ldots$

RESULTS AND DISCUSSION $\ldots \ldots \ldots \ldots \ldots \ldots \ldots \ldots \ldots \ldots \ldots \ldots \ldots$

Glass-Making Results . . . . . . . . . . . . . . . . 19

Joining Results $\ldots \ldots \ldots \ldots \ldots \ldots \ldots \ldots \ldots \ldots \ldots \ldots \ldots \ldots \ldots \ldots \ldots$

SUMMARY $\ldots \ldots \ldots \ldots \ldots \ldots \ldots \ldots \ldots \ldots \ldots \ldots \ldots \ldots \ldots \ldots \ldots \ldots \ldots$

REFERENCES $\ldots \ldots \ldots \ldots \ldots \ldots \ldots \ldots \ldots \ldots \ldots \ldots \ldots \ldots \ldots \ldots \ldots$

\section{FIGURES}

1. Prismatic compositional diagram showing the end components

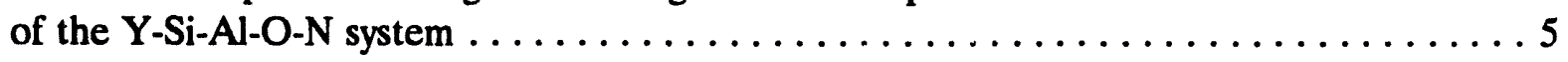

2. The ternary oxide phase diagram for the yttria, alumina, silica syster:, which is the back plane of the Y-SiAlON prism $\ldots \ldots \ldots \ldots \ldots \ldots \ldots \ldots \ldots \ldots \ldots$

3. First of three binary oxide phase diagrams that show the low-temperature liquids that form nearest the silica component $\ldots \ldots \ldots \ldots \ldots \ldots \ldots \ldots \ldots$

4. Second of three binary oxide phase diagrams that show the low-temperature liquids that form nearest the silica component $\ldots \ldots \ldots \ldots \ldots \ldots$ 
5. Third of three binary oxide phase diagrams that show the low-temperature liquids that form nearest the silica component $\ldots \ldots \ldots \ldots \ldots \ldots \ldots \ldots$

6. The classic SiAION phase nlane shows the numerous solid solutions (broad dark lines), which exist along compositional lines of constant metal/nonmetal ratio

7. The Y-Si-O-N phase plane indicates two low-temperature liquid-forming regions nearest the silica corner

8. Schematic diagram of the glass compositions developed during the INEL project. The shaded cylindrical space protrudes through approximately one-fourth of the prism's length, starting from the oxide plane

9. Vickers microhardness data indicate that hardness increases as nitrogen increases in the glass. The $15 \%$ nitrogen samples vere crystalline rather then glassy

10. Micrographs of (a) closed and (b) glass-filled Kyon 2000 joints. Thermal expansion mismatch cracks seen in $b$ are typical of the glass-filled joints

11. Flexural strengths of (a) glass-filled and (b) closed Kyon 2000 joints displayed as a function of temperature. The cross-hatched areas are the strengths of the unjoined original ceramics

12. Ceralloy glass-filled joint strengths are compared with similar joints in Kyon silicon nitride

13. HIPped and pressureless joint strengths are shown for samples of identical compositions .

14. Micrograph of the entire joint fracture surface. The original tensile edge is on the left

15. Micrograph showing high magnification near the tensile edge $\ldots \ldots \ldots \ldots \ldots$

16. Micrograph showing the location near the original neutral axis of the sample

17. Micrograph showing the location near the original compressive surface

18. Auger electron spectroscopy of the fracture surface of a sample fractured in dry nitrogen 
19. Auger electron spectroscopy of the fracture surface of a sample

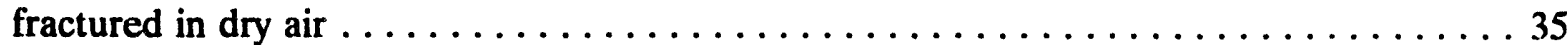

20. Slow crack growth time-to-failures are shown as a function of temperature for four different atmospheres. Only one set of standard deviation bars are shown for clarity

\section{TABLES}

1. Oxynitride glass compositions. Analyzed melt composition

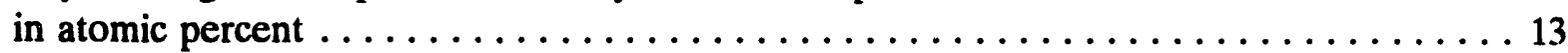

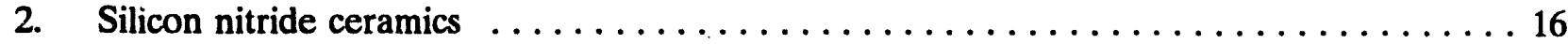

3. Fracture-toughness of joints prepared from various joining glasses and silicon nitrides 


\section{Joining of Silicon. Nitrides Using Oxynitride Glasses}

\section{INTRODUCTION}

Advanced ceramic materials are domestically available, environmentally compatible, potential substitutes for strategic and critical metals. Widespread application of ceramics such as silicon nitride has been partly limited by the inability to fabricate complex shapes and large parts that require the material to be joined. 'The purpose of the study was to investigate, develop, and test-under laboratory conditions--joining techniques based on the use of oxynitride glasses for silicon nitride ceramics. This study was conducted for the U.S. Department of the Interior, Bureau of Mines, by the Idaho National Engineering Laboratory (INEL), Idaho Falls, Idaho. 


\section{BACKGROUND}

Silicon nitride has significant potential as a high temperature engineering material. In order to realize this potential, it is important to understand the process of joining silicon nitride to silicon nitride, as well as to other materials. The best silicon nitrides have been made with combinations of high temperature and high pressure, either by HIPping or hot-pressing. Because of these processing constraints, it is difficult to fabricate large and complex-shaped parts in single pieces. Joining materials should approach the high temperature mechanical strength of silicon nitride so that large and complex parts can be made from small pieces.

In the mid-1970s, initial joining efforts employed simple, direct bonding methods. These techniques rely on sintering mechanisms and are dependent on impurities in the silicon nitride products, which form penetrating glasses. These glasses allow dissolution and recrystallization of the silicon nitride part surfaces [1].

Two significant disadvantages limited the success of these methods. First, silicon nitride parts surfaces must be extremely well-mated. Intimate contact must be maintained across the entire joint surface, or the resulting gaps cause large variations in joint strength. Second, impurity distribution and composition vary within silicon nitride pieces, causing inconsistent joining.

In another approach, silicon nitride powders were placed between silicon nitride surfaces and HIPped. Although reasonable strengths (310 MPa) were achieved, no great advantage resulted, because HIPping was required [2]. Brazing techniques using metals like zirconium also have been employed to join ceramic parts. However, high temperature strengths were limited by remnant metal or glass layers formed by reactions with impurities in the silicon nitride [3]. Related metal oxides or silicates, such as zirconia and zircon, have been used as joining materials with limited success [4].

Attempts were made to weld silicon nitride, using a plasma jet with alumina, aluminum nitride, or zirconium nitride as filler material. Although strengths of $250 \mathrm{MPa}$ were achieved, few practical joint designs are possible using this technique $[5,6]$.

The use of oxynitride glass as a joining media was originally suggested by Loehman [7], because of the oxynitride intergranular phase found in silicon nitrides. Bond strengths as high as $460 \mathrm{MPa}$ (comparable to those of silicon nitride) were achieved in room temperature fast fracture (fracture in the absence of slow crack growth) [8]. Several advantages were apparent from these early investigations. Since glass filled joints could flow and fill surface irregularities, well-mated surfaces were not required. Also because of this glass flow, pressureless joining of a variety of practical pieces became possible. In addition, by matching the composition of the joining glass to the grain boundary glassy phase in the silicon nitride, residual stresses in the joint were minimized. The existence of oxynitride glasses at the grain boundary in silicon nitride was recognized in the early 1970's by several researchers [9].

Oxide glasses were used to join a variety of silicon nitrides. During joining, these oxides react with silicon nitride grains and the intergranular glass to form an oxynitride glass $[7,8,10]$. Similar to silicon nitride sintered with $\mathrm{MgO}$ aids, joining glasses containing $\mathrm{MgO}$ were found to be less refractory than $\mathrm{Y}_{2} \mathrm{O}_{3}$ oxynitride glasses [11]. 
The oxynitride glasses of interest belong to the system containing the elements Si-Al-O-N system, also known as SiAlON. In crystalline SiAlONs, $\mathrm{Al}$ and $\mathrm{O}$ may reside on the same atomic positions as $\mathrm{Si}$ and $\mathrm{N}$ respectively, hence extensive substitutional solid solutions exist. In the oxynitride glass structures, nitrogen in the trivalent state is thought to replace divalent oxygen. The resultant nitrogen bridging forms three bonds, potentially increasing the crosslinking in the glass network [12]. It was shown that as nitrogen content increases glass properties improve; specifically, increased viscosity, higher glass transition temperature, increased hardness, and decreased coefficient of thermal expansion [13]. Prior to work at the Idaho National Engineering Laboratory (INEL), the maximum nitrogen content achieved was 7 at \% for yttrium-SiAION glasses.

Four time-dependent phenomena can be hypothesized for oxynitride glass filled joints: 1) classic creep flow, 2) devitrification, 3) slow crack growth (SCG) controlled by cavitation (viscous relaxation) at the crack tip, and 4) SCG controlled by stress aided corrosion (oxidation) of the joining glass. Slow crack growth is a time-dependent failure mechanism which can occur at temperatures well below the threshold for classic creep flow failure and at stresses significantly lower than those required for fast fracture. Slow crack growth failure is a problem of significant interest in structural ceramic materials. Previous research has identified several rate-controlling mechanisms of slow crack growth in ceramic materials.

Slow crack growth in silicon nitride and silicon carbide was examined in several recent studies [14-19]. Two predominant rate-controlling mechanisms--cavitation (viscous relaxation) [14-16] and stress-aided corrosion (oxidation) [17-19]--were identified.

These studies show that densification aids used in hot-pressing and sintering result in a glassy grain boundary phase. This glassy phase is subject to viscous deformation and cavity nucleation/growth at elevated temperatures [14]. Cavitation controlled SCG has been reported in hot-pressed $\mathrm{SiC}$, oxidized sintered SiC [15], and hot-pressed silicon nitride [16]. Other investigations have reported slow crack growth controlled by stress-aided corrosion. Non-oxide materials such as $\mathrm{SiC}$ and $\mathrm{Si}_{3} \mathrm{~N}_{4}$ oxidize readily at elevated temperatures, and their strengths decrease as a result [20]. In a study of several commercial hot-pressed $\mathrm{SiC}$ products, oxidation at the crack tip was reported to be SCG rate controlling [17]. In addition, reactive liquids may also control SCG, particularly as a result of attack on glassy grain boundary materials $[18,19]$.

The objective of the joining project at the INEL was to develop joining methods employing direct use of oxynitride glasses. As a consequence, it was necessary to first develop high-nitrogen oxynitride glasses. After glass making procedures were established, silicon nitride joining procedures were developed. In the latter stages of the joining work, joint characterization, analyses of failure mechanisms, and possible joint improvement methods were emphasized. 


\section{PHASE EQUILIBRIA OF THE Y-Si-AI-O-N SYSTEM}

As background information, it is necessary to discuss the phase equilibria of the Y-Si-Al-O-N system. From these data it becomes possible to anticipate the glass forming regions of this phase space, as well as the crystalline identity of devitrification products of any glass composition. Unfortunately, due to the complexity of this system, considerable uncertainty still exists.

In general, the Y-Si-Al-O-N system can be described in terms of a triangular prismatic space as shown in Figure 1. The oxide ternary $3 \mathrm{SiO}_{2}-2 \mathrm{Al}_{2} \mathrm{O}_{3}-2 \mathrm{Y}_{2} \mathrm{O}_{3}$ and the nitride ternary $\mathrm{Si}_{3} \mathrm{~N}_{4}-4 \mathrm{AlN}-4 \mathrm{YN}$ form the ends of the prism. The oxide ternary was relatively well established in the 1970's and is displayed in weight percent in Figure 2. The three binary oxide equilibrium diagrams shown in Figure 3, Figure 4, and Figure 5, respectively, are instrumental in understanding the sub-liquidus oxide phase equilibria.

High solidus temperatures $\left(1860^{\circ} \mathrm{C}\right.$ and above) characterize the $\mathrm{Al}_{2} \mathrm{O}_{3}-\mathrm{Y}_{2} \mathrm{O}_{3}$ binary. Consequently, glass formation in low $\mathrm{SiO}_{2}$ compositions is difficult, even though $\mathrm{Al}$ is an intermediate glass-former. The two binary systems containing silica (Figures 3 and 5) show relatively low temperature eutectics at high $\mathrm{SiO}_{2}$ contents. Similarly, in the ternary oxide diagram, low liquidus temperatures are seen in the $\mathrm{SiO}_{2}$ corner. It was anticipated from these diagrams that joining glass compositions would probably come from the high silica corner of the prismatic Y-Si-Al-O-N diagram.

The bottom rectangular plane of the phase equilibria prism, defined by the components $3 \mathrm{SiO}_{2}-2 \mathrm{Al}_{2} \mathrm{O}_{3}-4 \mathrm{AlN}-\mathrm{Si}_{3} \mathrm{~N}_{4}$, is known as the SiAlON system (from the elemental components $\mathrm{Si}, \mathrm{Al}$, $\mathrm{O}$, and $\mathrm{N}$ ). This system is well known for its extensive solid solutions formed along lines of constant metal:nonmetal ratio. Solid solution areas are shown as broad dark lines or darkened regions in Figure 6. Although the crystal structure remains the same within these solid solutions, crystalline lattice parameters vary continuously with chemical composition. Consequently, phase identification is more difficult because of shifting characteristic diffraction lines. Solid solutions extend from the SiAION plane into the Y-Si-Al-O-N prism and become space-filling regions.

The other phase equilibria plane of interest is that defined by the components $3 \mathrm{SiO}_{2}-\mathrm{Si}_{3} \mathrm{~N}_{4}-4 \mathrm{YN}-2 \mathrm{Y}_{2} \mathrm{O}_{3}$. This system, displayed in Figure 7, is fairly well known, although some controversies still exist. Solid solution lines extend from the compounds shown in this plane into the body of the prism. For example, a solid solution line exists through the prism between $\mathrm{Y}_{4} \mathrm{Si}_{2} \mathrm{O}_{7} \mathrm{~N}_{2}$ and $\mathrm{Y}_{4} \mathrm{Al}_{2} \mathrm{O}_{9}$.

In general, phase equilibria in the compositional prism of the Y-Si-Al-O-N system is not well known. The interior of the prism is a complex maze of solid solutions and possible quinary compounds. Although many researchers have contributed valuable bits of information, a number of controversies and inconsistencies remain. 


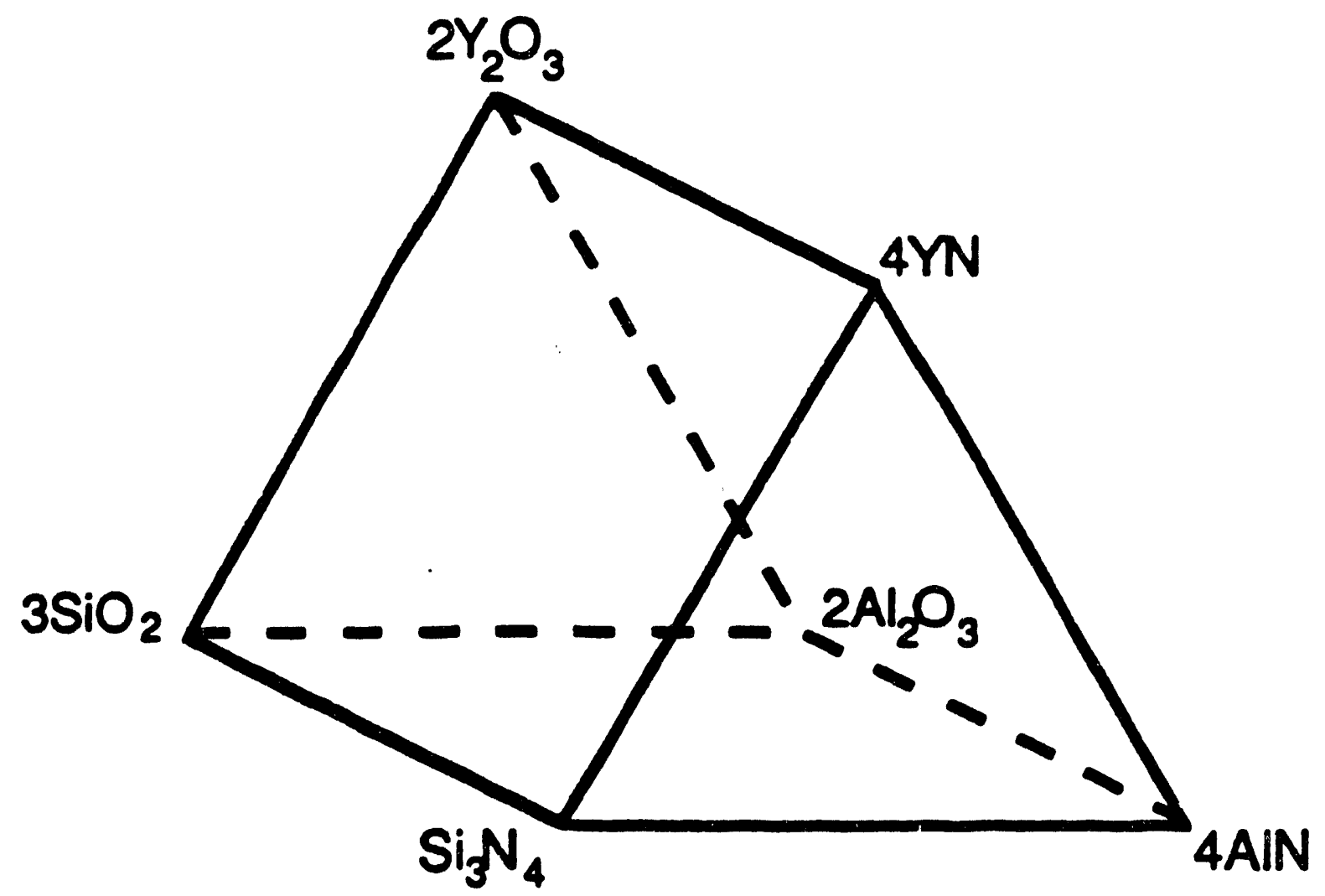

Figure 1. Prismatic compositional diagram showing the end components of the Y-Si-Al-O-N system. 


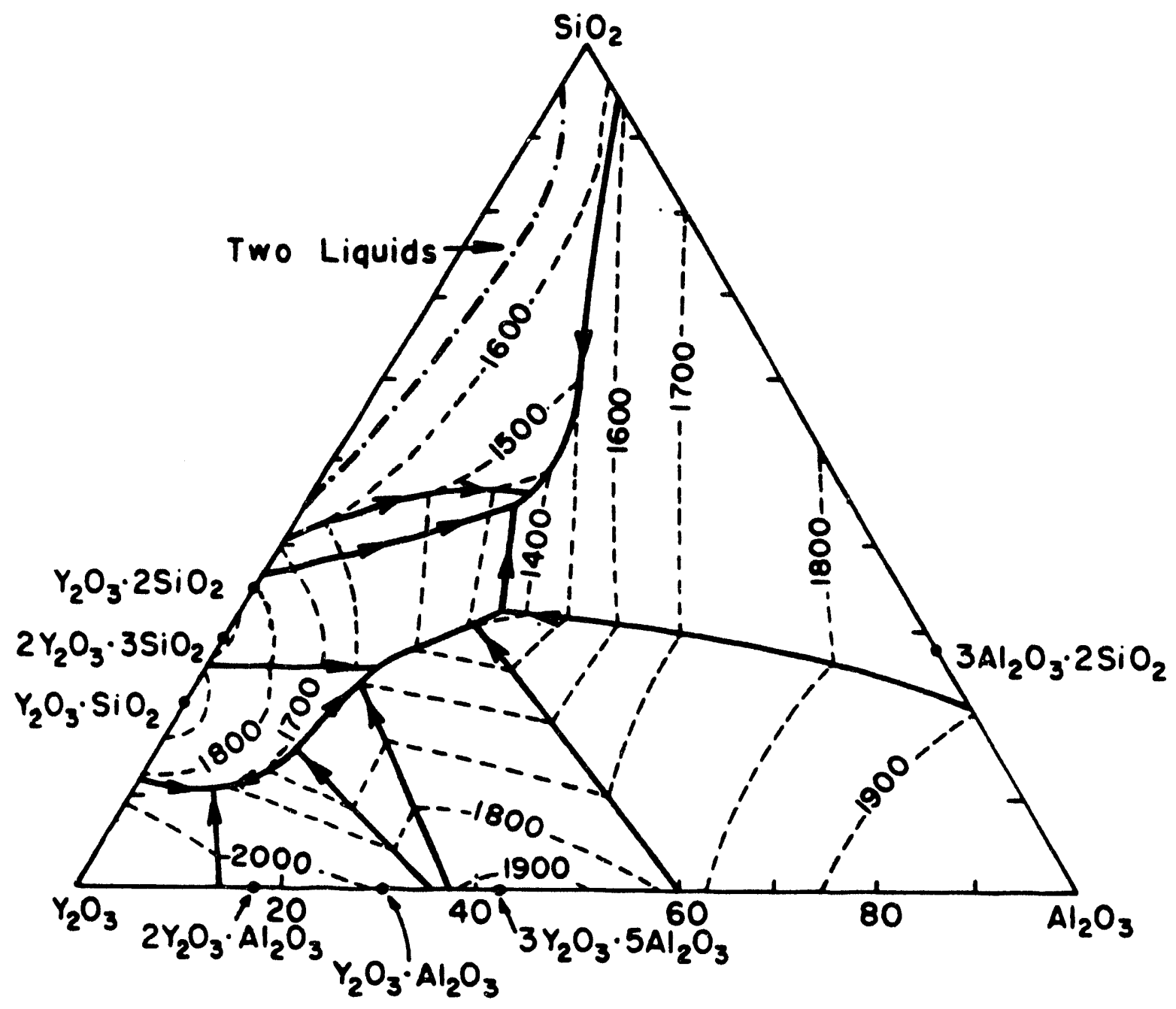

Figure 2. The ternary oxide phase diagram for the yttria, alumina, silica system, which is the back plane of the Y-SiAION prism. [A. Bondar and F. Ya. Galakhov, Izv. Akad. Nauk SSSR, Ser. Khim., 7, 1325, (1963), (see reference 21 for source of above phase diagram).] 


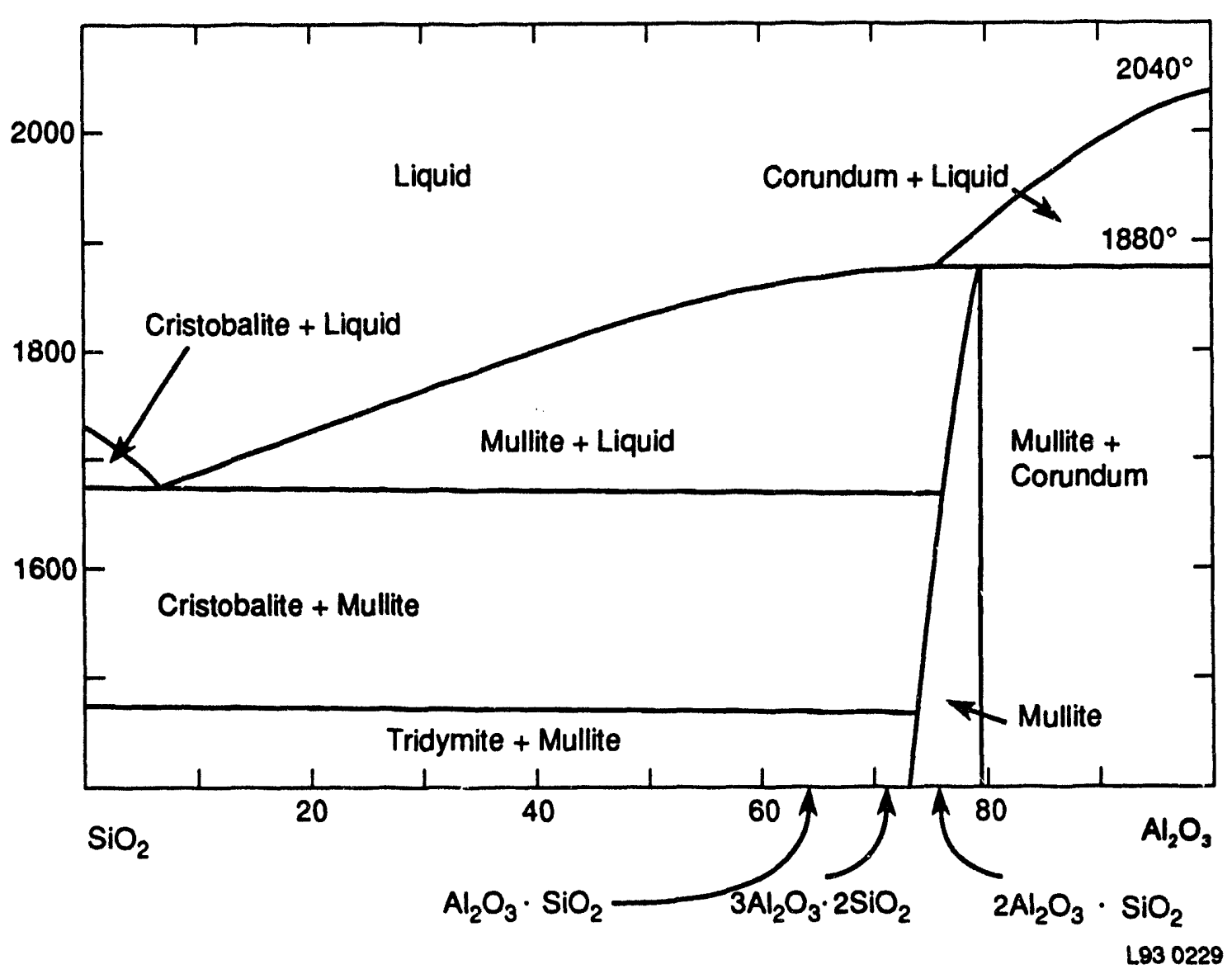

Figure 3. First of three binary oxide phase diagrams that show the low-temperature liquids that form nearest the silica component. [J. W. Welch, Nature, 186 (4724) 546 (1960); also Trans. Intern. Ceram, Congr., 7th London, 1960, 1961, pp. 197-206. See also: G. Trömel, K. H. Obst, K. Konopicky, H. Bauer, and I. Patzak, Ber. deut. keram. Ges., 34 (12) 401 (1957); E. C. Shears and W. A. Archibaid, Iron \& Steel, 27 (26) 61 (1954); N. L. Bowen and J. W. Greig, J. Am. Ceram. Soc., 7 (4) 242 (1924); (see reference 21 for source of above phase diagram).] 


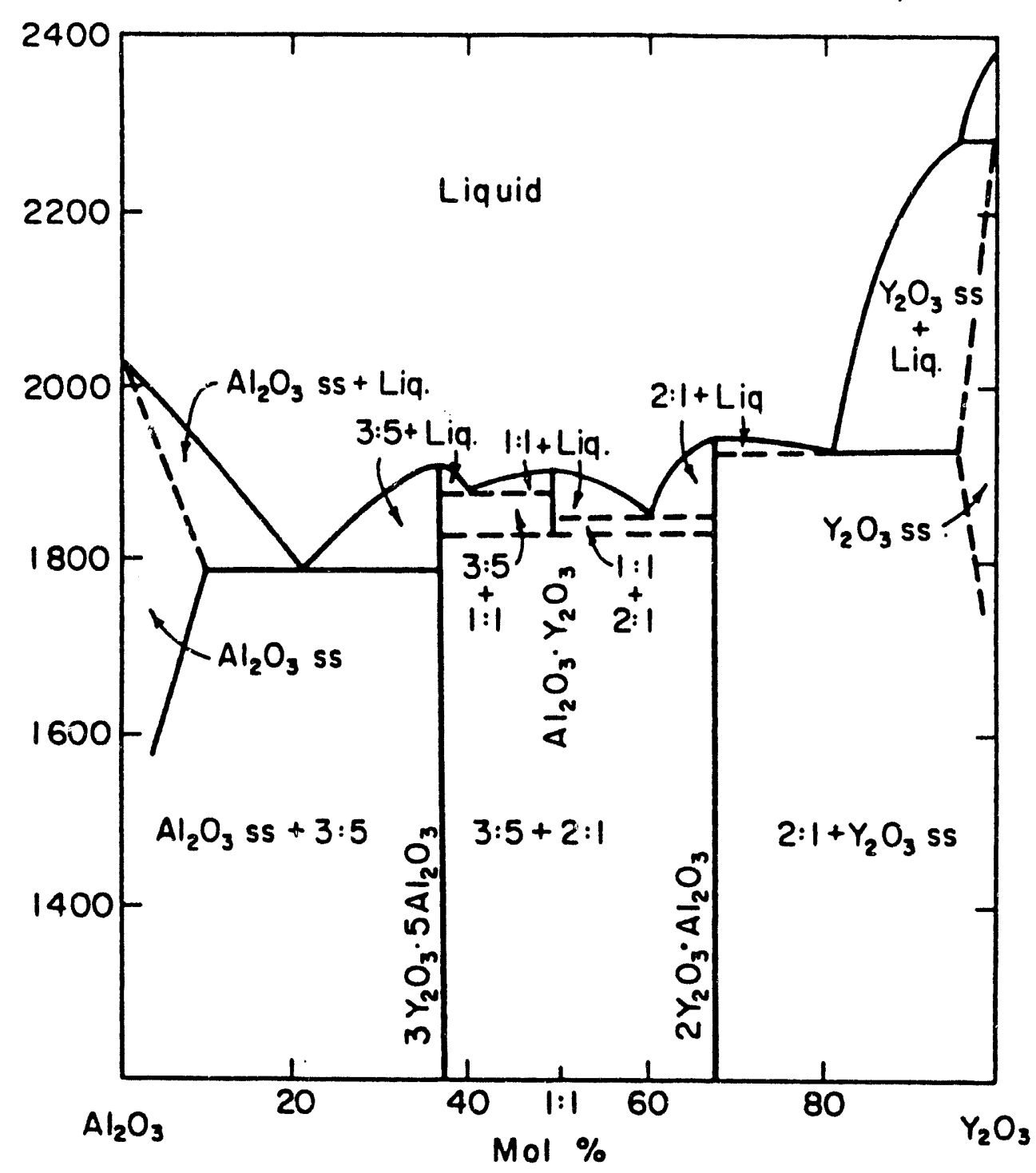

Figure 4. Second of three binary oxide phase diagrams that show the low-temperature liquids which form nearest the silica component. [T. Noguchi and M. Mizuno, Kogyo Kogaku Zasshi, 70, 6,839 , (1967), (see reference 21 for source of above phase diagram).] 


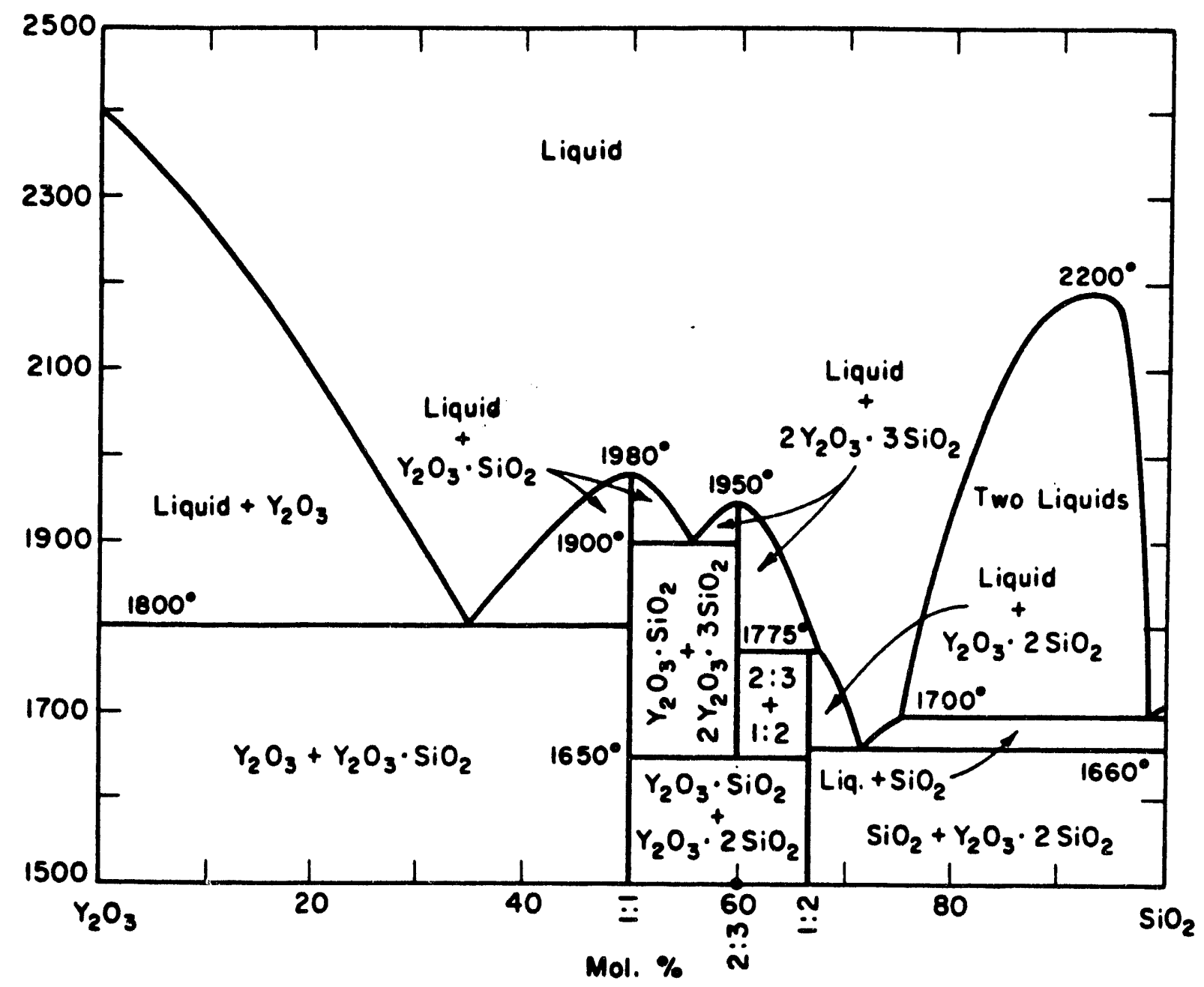

Figure 5. Third of three binary oxide phase diagrams that show the low-temperature liquids that form nearest the silica component. [N. a. Toropov, Trans. Intern, Ceram, Congr., 7th, Londom, 1960, p. 438; N. A. Toropov and I. A. Bondar, Izv. Akad. Nauk SSSR, Otd. Khim. Nauk, 4, 547, (1961), (see reference 21 for source of above phase diagram).] 


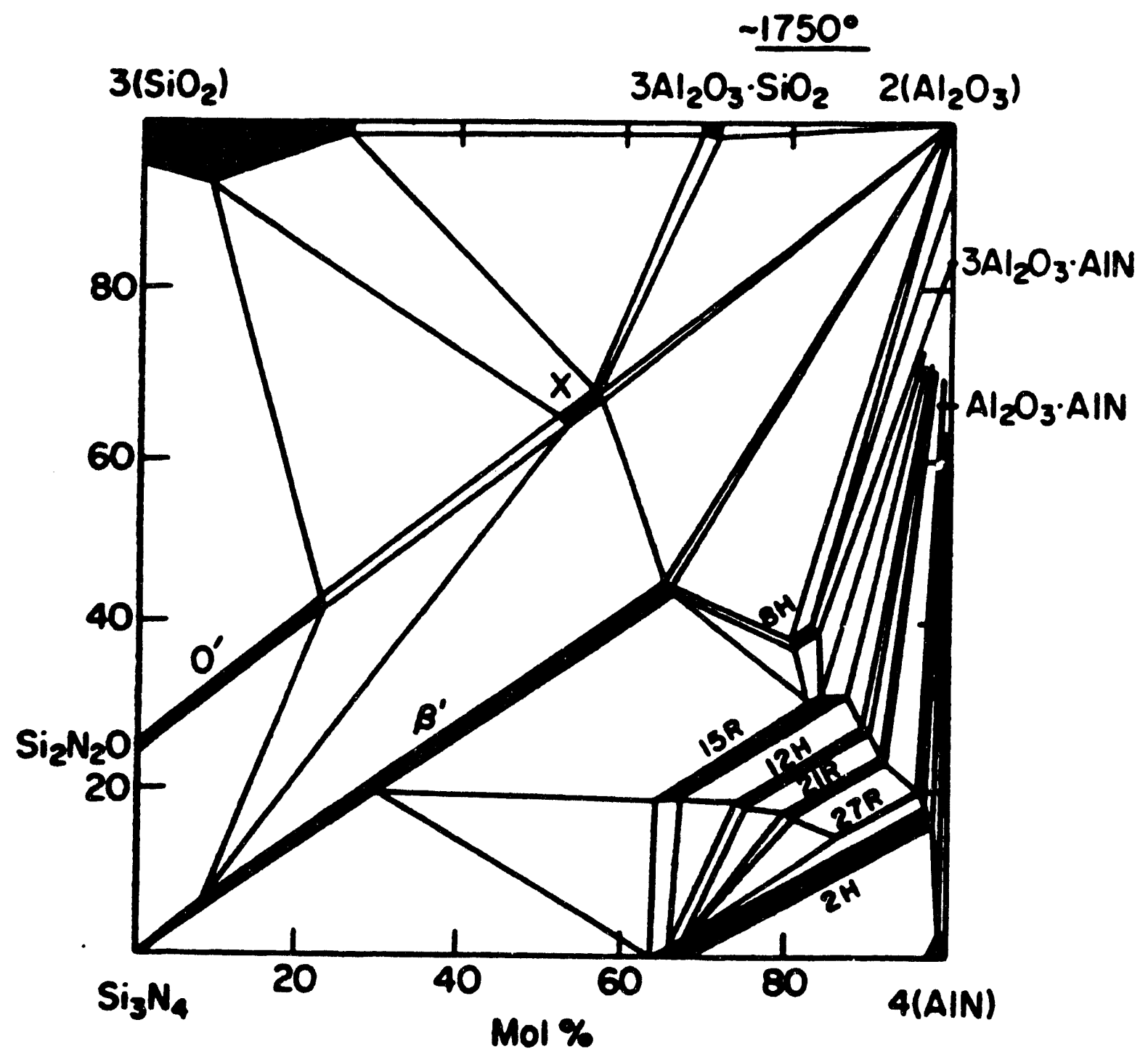

Figure 6. The classic SiAION phase plane shows the numerous solid solutions (broad dark lines), which exist along compositional lines of constant metal/nonmetal ratio. [K. H. Jack and W. I. Wilson, Nature (London), Phys. Sci, 283, 28, (1972), (see reference 21 for source of above phase diagram).] 


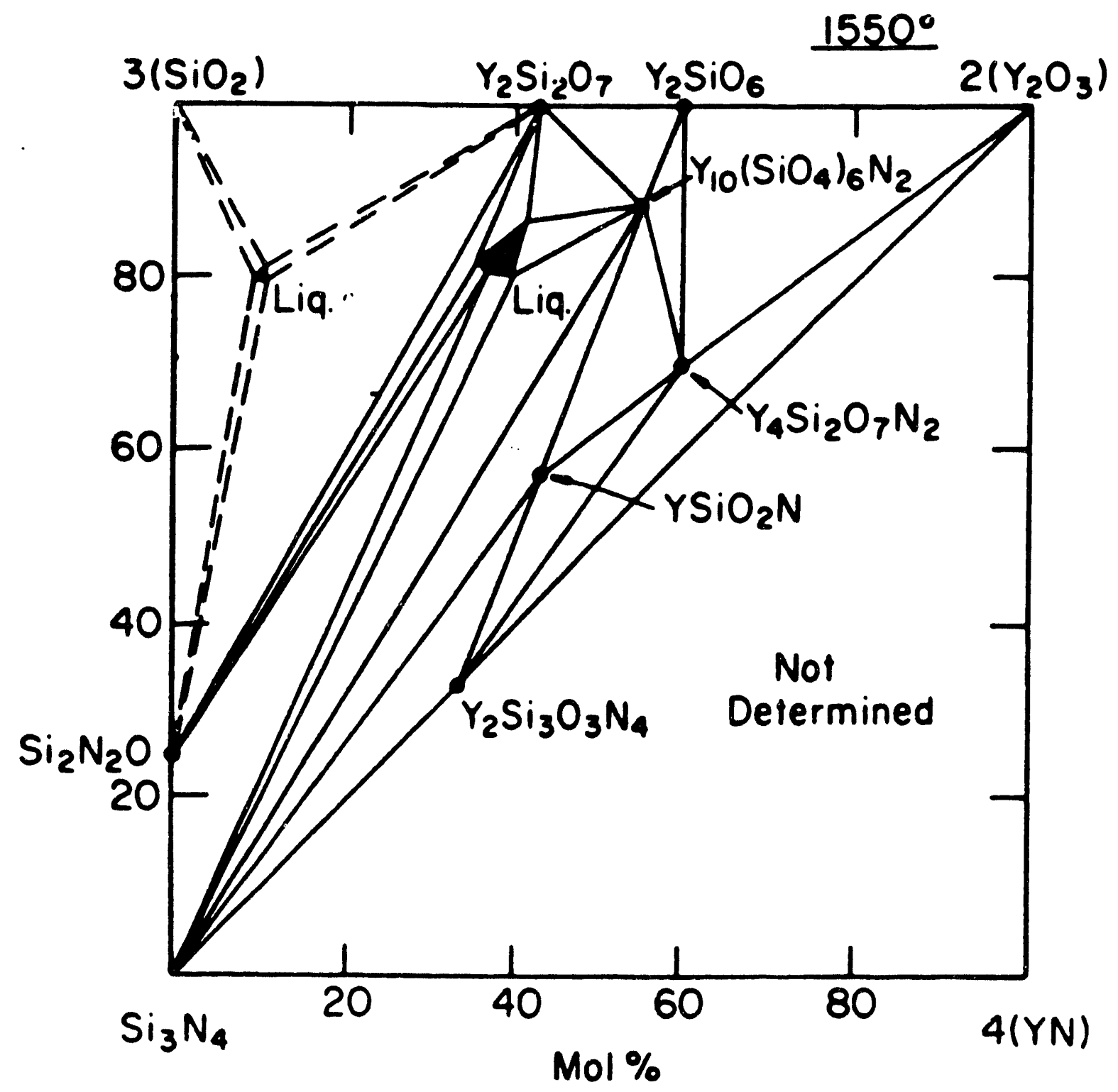

Figure 7. The Y-Si-O-N phase plane indicates two low-temperature liquid-forming regions nearest the silica corner. [L. J. Gauckler, H. Hohnke, and T. Y. Tien, J. Am. Ceram, Soc., 63 (1-2) 35, (1980), (see reference 21 for source of above phas ₹ diagram).] 


\section{EXPERIMENTAL PROCEDURES}

\section{Glass-Making Procedures}

For the experiments conducted at the INEL, a series of approximately thirty glass compositions were prepared from reagent-grade oxide and nitride powders. Some representative glass compositions are listed in Table 1 and are schematically displayed in the shaded cylindrical volume of the compositional prism in Figure 8. Each glass batch was dry mixed for two hours in a polyethylene bottle with silicon nitride milling balls. Powder compacts were cold isostatically pressed (CIPped) at $414 \mathrm{MPa}$ to reduce powder volume. Compacts were then placed in boron nitride crucibles for melting in the hot isostatic press (HIP).

Early in this project, HIPping was done through a subcontract with Gorham International in Gorham, Maine. The installation of a HIP at the INEL in FY85 resulted in significant refinement of the glass-making process. Initial HIP glass runs were produced at $1900^{\circ} \mathrm{C}$ under $207 \mathrm{MPa}$ of nitrogen pressure for one hour. As procedures at the INEL were refined, highest nitrogen glasses were produced at $1850^{\circ} \mathrm{C}$ and $124 \mathrm{MPa}$ of nitrogen. (For a more detailed description of HIP glassmaking by Mittl et al., see reference 22).

\section{Glass Characterization}

Oxygen and nitrogen contents were determined by a standard fusion analysis technique. Specimens were chosen from the interior of the melt because of boron nitride contamination in the outer $2 \mathrm{~mm}$ where the glass was in contact with the BN crucible.

Optical and scanning electron microscopy (SEM) were used to examine the microstructures of the glass melts. Energy dispersive spectroscopy (EDS) was used in conjunction with SEM to characterize the chemical gradients in these melts.

Elastic moduli of glasses were determined by ultrasonic wave velocity measurements. Longitudinal and shear wave velocities allow the calculation of Young's and Shear moduli, as well as Poisson's ratio. Since the stiffness moduli increase with increasing nitrogen bridging, they provide a measurement of the mechanical benefits of nitrogen additions.

Powdered glass samples were analyzed for crystalline and glass structures using $\mathrm{x}$-ray diffractometry (XRD) and Fourier transform infrared spectrometry (FTIR). XRD was used to identify the major crystalline phases and also to give some information about the amorphous structure of these glasses. FTIR provided chemical bonding information. Characteristic bonding changes were monitored to evaluate the effects of changing nitrogen content in these glasses.

Microhardness values were measured using Vickers indenters with a $100 \mathrm{~g}$ load on polished glass surfaces. Whereas the ultrasonic moduli measurements provided average changes in stiffness, microhardness measurements allowed localized evaluation of nitrogen bridging effects and variations in chemical compositions. 
Table 1. Oxynitride glass compositions. Analyzed melt composition in atomic percent.

\begin{tabular}{|c|c|c|c|c|c|c|c|}
\hline $\begin{array}{c}\text { Melt } \\
\text { No. }\end{array}$ & $Y$ & $\mathrm{Si}$ & $\mathrm{Al}$ & B & 0 & $\mathbf{N}$ & $C^{\prime}$ \\
\hline $3(5)$ & $\begin{array}{c}15.66^{b} \\
{[15.86]^{\mathrm{e}}}\end{array}$ & $\begin{array}{c}18.22 \\
{[18.45]}\end{array}$ & $\begin{array}{c}3.48 \\
{[3.52]}\end{array}$ & $\begin{array}{l}0.94 \\
{[0]}\end{array}$ & $\begin{array}{c}52.03 \\
{[54.57]}\end{array}$ & $\begin{array}{c}9.68 \\
{[7.60]}\end{array}$ & $\begin{array}{l}0.37 \\
{[0]}\end{array}$ \\
\hline $12(8)$ & $\begin{array}{c}15.96 \\
{[15.86]}\end{array}$ & $\begin{array}{c}18.62 \\
{[18.50]}\end{array}$ & $\begin{array}{c}3.55 \\
{[3.52]}\end{array}$ & $\begin{array}{l}0.11 \\
{[0]}\end{array}$ & $\begin{array}{c}51.93 \\
{[54.19]}\end{array}$ & $\begin{array}{c}9.83 \\
{[7.93]}\end{array}$ & $\begin{array}{l}0.05 \\
{[0]}\end{array}$ \\
\hline $12(3)$ & $\begin{array}{c}16.14 \\
{[16.04]}\end{array}$ & $\begin{array}{c}18.84 \\
{[18.71]}\end{array}$ & $\begin{array}{c}3.59 \\
{[3.56]}\end{array}$ & $\begin{array}{l}0.15^{d} \\
{[0]}\end{array}$ & $\begin{array}{c}48.84 \\
{[51.45]}\end{array}$ & $\begin{array}{c}12.44 \\
{[10.24]}\end{array}$ & $\begin{array}{l}0.05^{\mathrm{d}} \\
{[0]}\end{array}$ \\
\hline $1(1)$ & $\begin{array}{c}12.28 \\
{[12.33]}\end{array}$ & $\begin{array}{c}18.37 \\
{[18.45]}\end{array}$ & $\begin{array}{c}7.02 \\
{[7.05]}\end{array}$ & $\begin{array}{l}0.53 \\
{[0]}\end{array}$ & $\begin{array}{c}52.48 \\
{[54.27]}\end{array}$ & $\begin{array}{c}9.33 \\
{[7.60]}\end{array}$ & $\begin{array}{l}0.04 \\
{[0]}\end{array}$ \\
\hline $12(6)$ & $\begin{array}{c}15.98 \\
{[12.33]}\end{array}$ & $\begin{array}{c}14.28 \\
{[18.50]}\end{array}$ & $\begin{array}{c}9.14 \\
{[7.05]}\end{array}$ & $\begin{array}{l}0.16 \\
{[0]}\end{array}$ & $\begin{array}{c}48.36 \\
{[54.19]}\end{array}$ & $\begin{array}{l}12.08 \\
{[7.93]}\end{array}$ & $\begin{array}{l}0.06 \\
{[0]}\end{array}$ \\
\hline $3(1)$ & $\begin{array}{c}11.43 \\
{[11.48]}\end{array}$ & $\begin{array}{c}17.75 \\
{[17.82]}\end{array}$ & $\begin{array}{c}8.79 \\
{[8.83]}\end{array}$ & $\begin{array}{l}0.66 \\
{[0]}\end{array}$ & $\begin{array}{c}50.46 \\
{[53.41]}\end{array}$ & $\begin{array}{l}10.91 \\
{[8.46]}\end{array}$ & $\begin{array}{l}0.08 \\
{[0]}\end{array}$ \\
\hline $12(7)$ & $\begin{array}{c}11.52 \\
{[11.48]}\end{array}$ & $\begin{array}{c}17.95 \\
{[17.88]}\end{array}$ & $\begin{array}{c}8.86 \\
{[8.83]}\end{array}$ & $\begin{array}{l}0.14^{d} \\
{[0]}\end{array}$ & $\begin{array}{c}51.24 \\
{[52.98]}\end{array}$ & $\begin{array}{l}10.29 \\
{[8.83]}\end{array}$ & $\begin{array}{l}0.05^{\mathrm{d}} \\
{[0]}\end{array}$ \\
\hline $12(1)$ & $\begin{array}{c}15.15 \\
{[15.00]}\end{array}$ & $\begin{array}{c}15.15 \\
{[15.00]}\end{array}$ & $\begin{array}{c}10.10 \\
{[10.00]}\end{array}$ & $\begin{array}{l}0.18 \\
{[0]}\end{array}$ & $\begin{array}{c}41.37 \\
{[45.00]}\end{array}$ & $\begin{array}{c}18.05 \\
{[15.00]}\end{array}$ & $\begin{array}{l}0.04 \\
{[0]}\end{array}$ \\
\hline
\end{tabular}

a. In addition to 100 atomic percent.

b. Analyzed resulting composition.

c. Intended batch composition.

d. Approximate value, not analyzed.

Note: Analyzed composition was determined by Leco fusion analysis of the melt produced in the hot-isostatic-press (HIP). Batch composition is the designed composition of the powder mixture from which the glasses were made. 


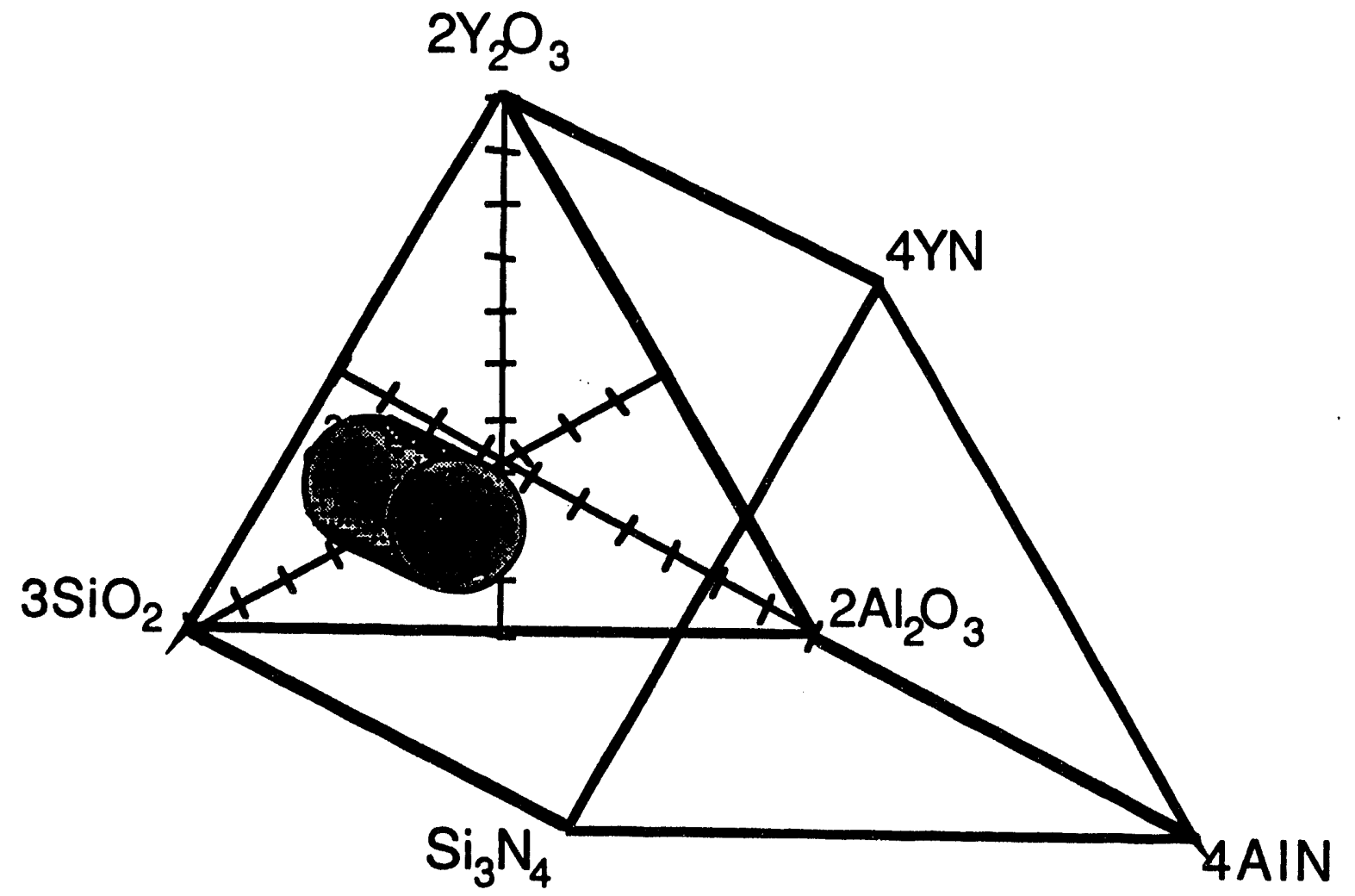

Figure 8. Schematic diagram of the glass compositions developed during the INEL project. The shaded cylindrical space protrudes through approximately one-fourth of the prism's length, starting from the oxide plane. 
Microindentation fracture toughness measurements were also made. In this test, small cracks were generated at the four points of the diamond-shaped (Vickers) indenter. The length of the radial crack under a particular load is inversely proportional to the fracture toughness of the material. This technique provides a reasonable measurement of material toughness and is adequate to determine the relative effect of increasing nitrogen in a series of glasses.

Differential thermal analysis (DTA) was performed to determine the glass transition temperatures $\left(\mathrm{T}_{2}\right)$, and the devitrification (growth of crystals) behaviors of various glass compositions. In this technique, the differential temperature between a standard material and the specimen being analyzed provides information about the endothermic and exothermic events in the specimen.

\section{Joining Procedures}

Initial joining experiments were HIPped along with glass-making runs at $1900^{\circ} \mathrm{C}$ and 207 $\mathrm{MPa}$ of nitrogen pressure. At this temperature and pressure very thin joints resulted. In order to create a variety of joint thicknesses, boron nitride shims were placed between the silicon nitride pieces. These preliminary tests indicated that silicon nitride joining using high-nitrogen oxynitride glasses was feasible.

Three commercially available silicon nitride ceramics were chosen for joining: one sintered with yttria and alumina aids, another hot-pressed with primarily yttria, and the third hot-pressed with magnesia and alumina aids. Relevant processing and compositional data are specified in Table 2. In particular, the amounts and types of glassy grain boundary phases in these silicon nitrides are important because of the reactions of these phases with the joining glass. These grain boundary phases contain the bulk of the additives present to enhance densification. Three methods of applying the glass joint layer were examined: glass-slice approach, capillary infiltration, and glass-paste application.

In the glass slice technique, a thin plate of oxynitride glass was placed between two pieces of commercial silicon nitride. At temperatures between $1500^{\circ}$ and $1600^{\circ} \mathrm{C}$, the joining glass softened and flowed to uniformly cover the entire joint surface.

In a second approach, capillary forces were used to draw molten glass into the joint between two silicon nitride parts. This method required temperatures of approximately $1800^{\circ} \mathrm{C}$ to provide sufficiently low viscosities. In the absence of high nitrogen pressures the joining glasses tended to vaporize and/or decompose at these high temperatures.

Finally, a glass-paste technique was tested by applying powdered glass in an organic binder to the joint surface. Binder material was subsequently removed through a low temperature calcination step. This process also required temperatures of approximately $1800^{\circ} \mathrm{C}$.

The glass-slice technique proved to be the best of the three, because it is simple and reproducible. (More procedural detail can be found in Coon, reference 23.) 
Table 2. Silicon nitride ceramics.

\begin{tabular}{llllll}
\hline & & & \multicolumn{3}{c}{ Additive (wt\%) } \\
\cline { 5 - 6 } Ceramics & Manufacturer & Densificatio. & $\mathrm{MgO}$ & $\mathrm{Y}_{2} \mathrm{O}_{3}$ & $\mathrm{Al}_{2} \mathrm{O}_{3}$ \\
\hline NC-132 & $\begin{array}{l}\text { Norton Company } \\
\text { Kyon } 2000\end{array}$ & Hot-pressed & $0.4-1.0$ & - & $0.2-0.5$ \\
Ceralloy 147Y-2 & $\begin{array}{l}\text { Kennametal, Inc. } \\
\text { Kaleigh, NC) }\end{array}$ & Sintered & $\leq 0.8$ & $\sim 6$ & $\sim 10$ \\
& $\begin{array}{l}\text { Ceradyne, Inc. } \\
\text { (Santa Ana, CA) }\end{array}$ & Hot-pressed & - & 4 & "Trace" \\
\hline
\end{tabular}


In addition to joining in the HIP under nitrogen pressure, a technique was developed for pressureless joining. Pressureless joining was accomplished using the glass-slice method in a furnace with flowing nitrogen. A buffer powder was used to adjust the partial pressures of covering gasses to inhibit the decomposition of the sample. Joining was also accomplished without a buffer by use of a muffle tube to isolate the sample from the furnace atmosphere.

\section{Joint Characterization}

The microstructures of various joints were investigated by a combination of optical and SEM techniques, similar to the analysis of the glasses previously described. Joint devitrification and reactions at the interface between the joining glass and the silicon nitride were analyzed by several SEM techniques, including back-scattered electron (BSE) imaging and EDS. BSE provides atomic number contrast, showing heavy element concentrations, like yttrium.

Auger electron spectroscopy and x-ray photoelectron spectroscopy (XPS) were used to analyze the surface chemistry of joint fracture surfaces. EDS gives average chemical composition from a sample volume having substantial depth (microns). Auger and XPS provide elemental identities and bonding information about the first few atomic layers of the surface. Consequently these analytical techniques are very useful for fracture studies.

Transmission electron microscopy was used to examine the structure and chemistry of selected joint interfaces without fracture. Although XRD was used to characterize the crystalline and amorphous phase contents of the commercial silicon nitride, it was not possible to interrogate actual glass joints by this method because they are too small. However, electron diffraction and imaging in the TEM provided ample resolution for examining in situ joint interfaces.

Room temperature fracture toughness of joined and unjoined silicon nitride samples were measured with a fractometer. During sample preparation for this test, a diamond wafering saw cuts away part of the sample, so that a v-shaped joint or ceramic test area remains. Stable crack growth through the joint or ceramic is then driven by a small instumented hydraulic jack. The jack gradually forces the crack to open. Only the load at failure and the width of the sample are necessary to calculate the fracture toughness, according to the relationship developed by Barker [24]. Relative to microindenta...on toughness measurements, this technique is significantly more reliable and reproducible. However, it is also much more difficult and time consuming.

Elevated temperature flexural strengths were measured in a four-point bend geometry in accordance with MIL-STD-1942A. An Instron tension/compression load frame was modified for elevated temperature and controlled atmosphere testing. Modulus-of-rupture (MOR) bars, with dimensions of $3 \times 4 \times 45 \mathrm{~mm}$ were machined according to the procedures and tolerances specified by the standard. Fast fracture flexural strengths of joints with different joining glass composition were tested as a function of temperature. In addition to testing joined samples, unjoined silicon nitride specimens were tested under identical conditions.

Two time-dependent failure modes (creep and slow crack growth) were considered in the latter stages of the joint testing. Time-to-failures (TTFs) for these modes were measured as a function of temperature and atmosphere under constant load in the four-point bend flexural geometry. The load necessary to produce an initial flexural stress equal to $50 \%$ of the nominal 
maximum flexural strength was arbitrarily chosen as the constant load for tirie-dependent failure testing. For example, for Ceralloy 1(1) joints the chosen initial stress was $165 \mathrm{MPa}$. This same initial stress was created in each test sample by measuring exact dimensions and calculating the appropriate load in each case. Time to failure was then measured for various temperatures and atmospheric conditions. 


\section{RESULTS AND DISCUSSION}

\section{Glass-Making Results}

In general, HIPped glasses contained at least as much nitrogen as in the original batch compositions. Apparently, the nitrogen pressure of the HIP was sufficient to provide a nitrogen activity gradient sufficient to diffuse additional nitrogen into the melt. Otherwise, the differences between the analyzed and the calculated batch compositions were minor, as shown in Table 1 . This suggests that compositions were not significantly altered during the various processing stages and that the analytical techniques had reasonable accuracy.

Optical microscopy and SEM observation showed cloudy regions that consisted of bubbles, precipitate crystals, or undissolved grains of original powder. From concurrent EDS measurements, crystalline particles were tentatively identified as either undissolved silicon nitride or SiAlON precipitates grown during cooling.

Phase composition analysis by XRD indicated increasing crystalline particulate content with increasing silicon nitride in the batch mix. The most likcly identity of these particulates was $B-S_{3} N_{4}$, but also possibly $\beta^{\prime}-S i A I O N$. Because $\beta^{\prime}-S_{i A I O N}$ has an identical crystal structure, it is difficult to tell the difference between it and $\mathrm{B}_{-} \mathrm{Si}_{3} \mathrm{~N}_{4}$. In high nitrooen content samples, yttrium nitrogen melilite $\left(\mathrm{Y}_{2} \mathrm{Si}_{3} \mathrm{~N}_{4} \mathrm{O}_{3}\right)$ was found with some minor additional phases. The amorphous structures of glasses with different nitrogen contents appeared to be similar, according to the XRD indicators.

Bonding evidence from FTIR examinations also showed increasing crystallinity with increasing nitrogen content. In addition, with increasing nitrogen content, amorphous absorption peaks became broader and shifted toward lower wavenumbers. This is an indication of increasingly mixed oxygen/nitrogen bonding in these glasses.

Vickers microhardness testing indicated that hardness values increased as nitrogen content increased for the glass samples. The 15 weight percent samples were nearly all crystalline and microhardness values were relatively low. These data correlate well with previous findings $[12,25,26]$ and support the theory that the substitution of nitrogen for oxygen in the glass structure increases the number of bridging bonds in the glass network, causing greater stiffness. Microhardness data as a function of nitrogen content are displayed in Figure 9. Note that samples up to 12 weight percent were predominantly glassy with some very fine isolated crystallinity. Isolated crystallinity had little effect on the microhardness values.

Microindentation toughness measurements showed that toughness also increased as nitrogen content increased. $\mathrm{K}_{\mathrm{lc}}$ measurements for a glass series having increasing nitrogen content (melt compositions $1(1)$ through $1(5), 17$ to $60 \mathrm{eq} \% \mathrm{~N}$ ) were $1.17,1.45,1.33,1.57$, and $1.92 \mathrm{MPa} \cdot \mathrm{m}^{1 / 2}$. Standard deviations of measurements were minor relative to the differences observed between these glasses. This trend is again indicative of the effect of increased bridging (or crosslinking) of the glass network resulting from nitrogen additions. 


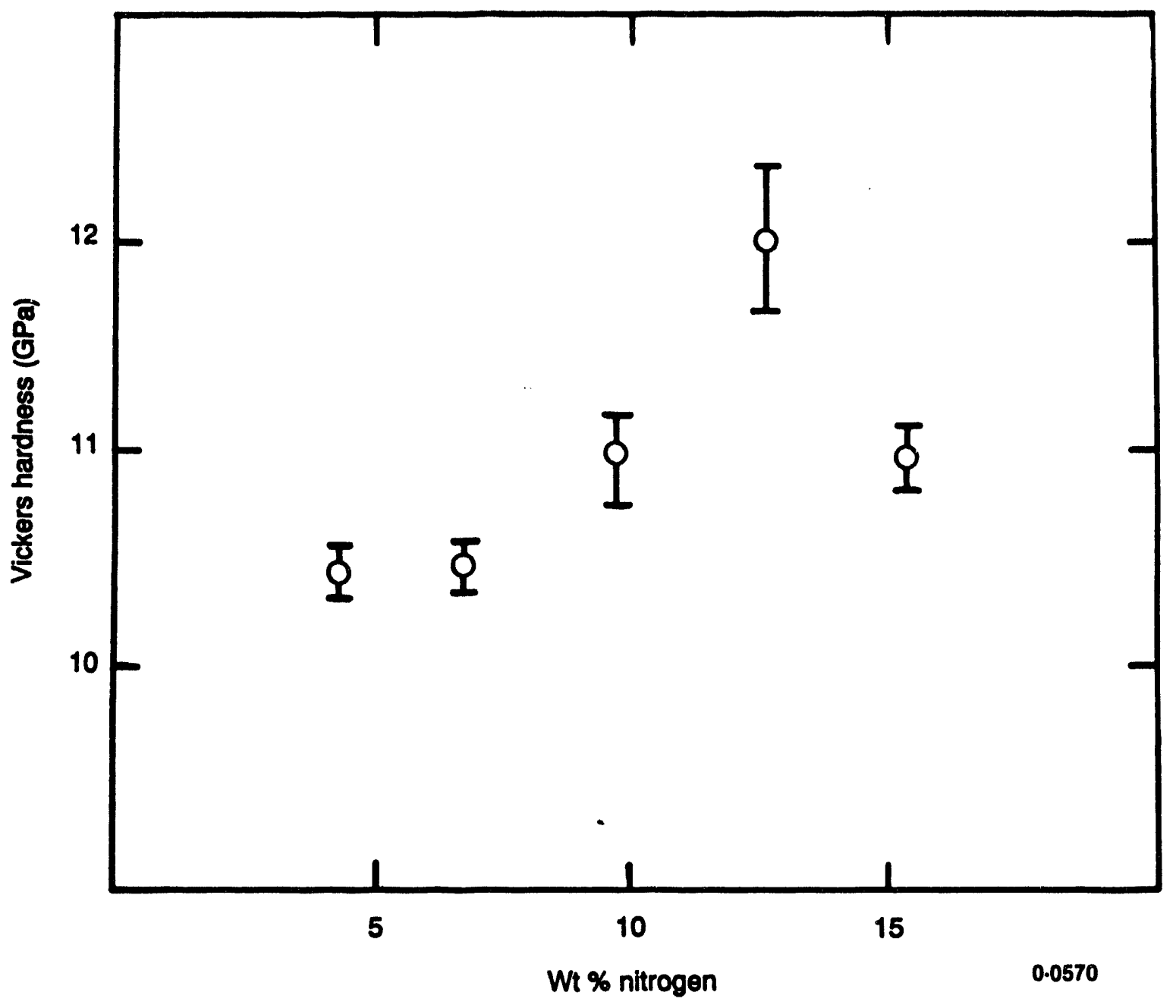

Figure 9. Vickers microhardness data indicate that hardness increases as nitrogen increases in the glass. The $15 \%$ nitrogen samples were crystalline rather then glassy. 
DTA measurements showed that the glass transition temperatures $\left(T_{p}\right)$ of these glasses increased as nitrogen content increased. The $T_{g}$ is the transition temperature between solid (brittle) glass behavior and visco-elastic behavior. $T_{g}$ has a characteristic viscosity. Although under different conditions transition actually occurs over a finite range of temperatures and viscosities, a mean viscosity is often considered to be $10^{13}$ Poise. Since the $T_{8}$ of the oxynitride glasses increases with increasing nitrogen, it may also be concluded that at any particular temperature, glass viscosity increases with increasing nitrogen content.

The refractive indices and densities of glasses as a function of nitrogen content were also determined. The refractive indices varied from 1.748 to 1.853 and the densities ranged from 3.67 to $4.06 \mathrm{~g} / \mathrm{cm}^{3}$. The refractive index increased as nitrogen content increased, while density increases resulted from increasing yttrium content. The ionic refractivity of nitrogen ions in the glasses was calculated to be 66.6 , which is consistent with nitrogen ions in threefold coordination with silicon ions [27].

Considerable effort was invested throughout this project to gain an understanding of the devitrification behavior of the Y-Si-Al-O-N glasses. Although much was learned, the extreme complexity of this system precludes any succinct description. Furthermore, it is fair to say that significant controversies still exist. While the knowledge gained in working with this system provides a significant basis for future studies (composites), a continuing learning process is anticipated.

\section{Joining Results}

Two types of effective joints were generated by the various methods previously described: closed joints, and glass-filled joints. Closed joints were characterized by very thin polycrystalline joint regions which were relatively indistinguishable from the neighboring silicon nitride. Glass-filled joints were easily seen as distinct layers with low magnification optical examination.

Joints in the sintered silicon nitride, Kyon 2000, prepared at high joining temperatures (approximately $1725^{\circ} \mathrm{C}$ ) were characteristically closed joints. A low magnification micrograph of a closed Kyon joint is displayed in Figure 10a. TEM examination revealed a fine-grained joint layer in these samples. Its appearance was similar to that of the original silicon nitride. The joint interface was nearly invisible optically. Neither of the hot-pressed silicon nitrides was reliably joined by these higher temperature (closed) joining procedures. Extensive void formation typically resulted from closed joint attempts with both of the hot-pressed silicon nitrides (NC-132 and Ceralloy 147Y-2). However, in some instances, attempts to form closed joints in the $\mathrm{Mg}$-aided hot-pressed silicon nitride (NC-132) were partially successful.

Analytical results indicate that this closed joint behavior is probably related to the composition and amount of the glassy grain boundary phase in these silicon nitride products. The sintered silicon nitride (Kyon 2000) contained a greater volume percent of glass and a more reactive glass composition than either of the hot-pressed materials. Sintered silicon nitrides characteristically must contain such glasses to provide densification in the absence of applied pressure. The NC-132 material had intermediate glass volume and reactivity, resulting in somewhat intermediate closed joint behavior. Apparently, closed joining procedures may not be 

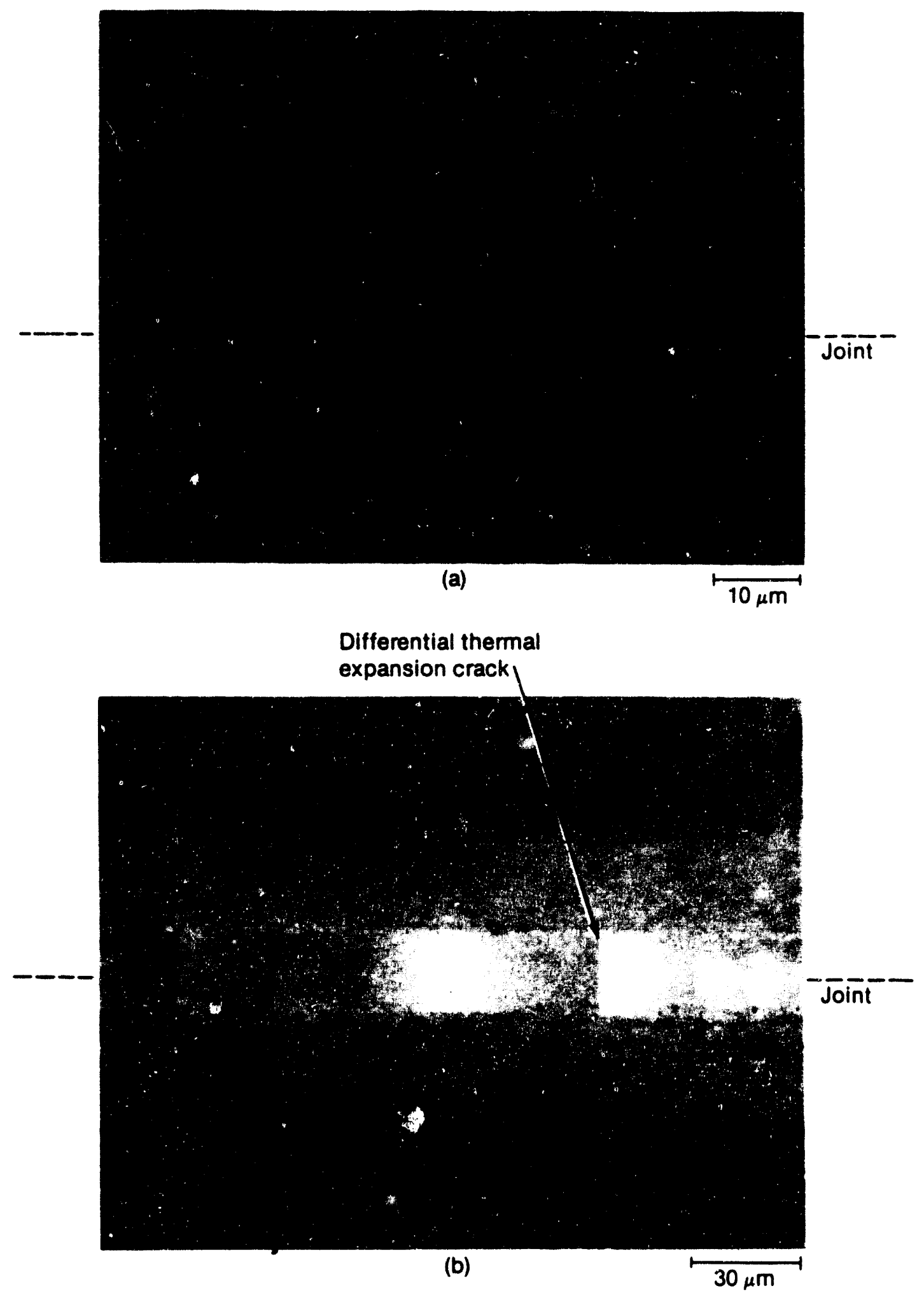

Figure 10. Micrographs of (a) closed and (b) glass-filled Kyon 2000 joints. Thermal expansion mismatch cracks seen in b are typical of the glass-filled joints. 
applicable to all silicon nitrides. It is important to note that the silicon nitride products which have the least remnant glass also have the best mechanical properties at elevated temperatures.

Successful glass-filled joints were made with all three of the commercial silicon nitrides. Joining temperatures between 1500 and $1600^{\circ} \mathrm{C}$ allowed the joining glass to flow throughout the joint area, without excessive fluidity or loss of material. Depending upon the processing temperature and the amount of joining glass used, joints with thicknesses between 10 and $30 \mu \mathrm{m}$ were produced. A glass-filled joint in Kyon 2000 having an approximate thickness of $30 \mu \mathrm{m}$ is shown in Figure 10b. Notice in addition to the amorphous joint layer there is a reaction zone which extends approximately another $30 \mu \mathrm{m}$ into each of the silicon nitride pieces. In this zone, the composition of the grain boundary glass was modified by the joining glass. A gradient in composition within the glass-filled joint was also detected by Auger analysis. Higher silicon content was found near the joint-part interface relative to the center of the joint.

Room temperature fracture toughness values of closed and glass-filled joints were comparable to the toughness values measured for the unjoined silicon nitrides. Table 3 shows the toughness values measured by the fractometer at room temperature as a function of various joining conditions. In general, toughness values ranged between 4 and $5.5 \mathrm{MPa}^{1 / 2}$ for all samples.

As previously noted, numerous voids formed in most of the Ceralloy $147 \mathrm{Y}-2$ samples joined at higher temperatures. The toughness values of these samples were predictably low. In several instances, lower joining pressure corresponded with higher toughness. This behavior is not well understood. In most cases, high toughness values resulted when the crack deviated from the joint area into the silicon nitride piece. In these instances the crack traveled through the reaction zone in the ceramic, as previously described. It is hypothesized that residual stresses and consequent microcracking in this reaction zone are responsible for this behavior. In some cases, the growing crack was apparently deflected away from the joint by defects, or, possibly, by thermal expansion mismatch cracks. Predictabiy, cracks which traveled through the ceramic resulted in toughness values similar to the unjoined ceramic.

Flexural strengths of joints were comparable to the strengths in fast fracture of the as-received silicon nitrides. Flexural strength data for two different joining glass compositions and the unjoined ceramic (Kyon) are shown in Figure 11a. The cross-hatched area in this plot is the range of strengths observed in the unjoined ceramic. Note that joints using glass composition 1(1) were approximately equal in strength up to $1000^{\circ} \mathrm{C}$, where they began to soften and flow. In contrast, the 3(5) composition glass had roughly half the strength but retained that strength to a higher temperature. (The strengths of closed joint samples are shown in Figure 11b.) In this instance, the joining glass composition seems to have minimal effect on the joint strength. A significantly wider distribution of strengths were observed, but strengths were maintained to higher temperatures. This distribution of strengths probably resulted from less uniform bonding conditions across the joint surface.

The mean room temperature strength of glass-filled Ceralloy $147 \mathrm{Y}-2$ joints was nearly identical to that of the Kyon joints. At elevated temperatures, slightly lower comparable strengths were recorded. Similar to the Kyon joints, brittle failure was observed up to $1000^{\circ} \mathrm{C}$. Above that 
Table 3. Fracture-toughness of joints prepared from various joining glasses and silicon nitrides.

\begin{tabular}{|c|c|c|c|c|c|}
\hline \multicolumn{3}{|c|}{ Joining conditions } & \multicolumn{3}{|c|}{$\begin{array}{l}\text { Joint fracture toughness } \\
\left(\mathrm{MPa} \cdot \mathrm{m}^{1 / 2}\right)\end{array}$} \\
\hline Silicon nitride & $\begin{array}{l}\text { Temperature } \\
\left({ }^{\circ} \mathrm{C}\right)\end{array}$ & $\begin{array}{l}\text { Pressure, } \\
\mathrm{MPa}\end{array}$ & $\begin{array}{c}\text { Glass } 1 \\
\text { (1) }\end{array}$ & $\begin{array}{c}\text { Glass } 3 \\
\text { (1) }\end{array}$ & $\begin{array}{c}\text { Glass } 3 \\
(5)\end{array}$ \\
\hline Kyon 2000 & $\begin{array}{l}1,725 \\
1,600\end{array}$ & $\begin{array}{l}207 \\
138\end{array}$ & $\begin{array}{l}4.7^{a} \\
4.4^{a}\end{array}$ & $\begin{array}{l}5.1^{\star \prime} \\
-\end{array}$ & $\begin{array}{l}4.1^{2} \\
4.6\end{array}$ \\
\hline NC-132 & $\begin{array}{l}1,725 \\
1,725 \\
1,600\end{array}$ & $\begin{array}{r}138 \\
21 \\
138\end{array}$ & $\begin{array}{l}- \\
4.0^{\circ} \\
3.2^{\mathrm{a}}\end{array}$ & $\begin{array}{l}4.6^{a} \\
3.3 \\
-\end{array}$ & $\begin{array}{l}2.3 \\
4.2^{\mathrm{a}} \\
3.7^{\mathrm{a}}\end{array}$ \\
\hline Ceralloy $147 \mathrm{Y}-2$ & $\begin{array}{l}1,725 \\
1,725 \\
1,600\end{array}$ & $\begin{array}{r}138 \\
21 \\
135\end{array}$ & $\begin{array}{l}- \\
1.0 \\
4.0\end{array}$ & $\begin{array}{l}<1.0 \\
-6 \\
-\end{array}$ & $\begin{array}{c}<1.0 \\
5.6^{b} \\
-\end{array}$ \\
\hline $\begin{array}{l}\text { a. Crack deflectio } \\
\text { b. Broke during g! }\end{array}$ & icon nitride obs & & & & \\
\hline
\end{tabular}




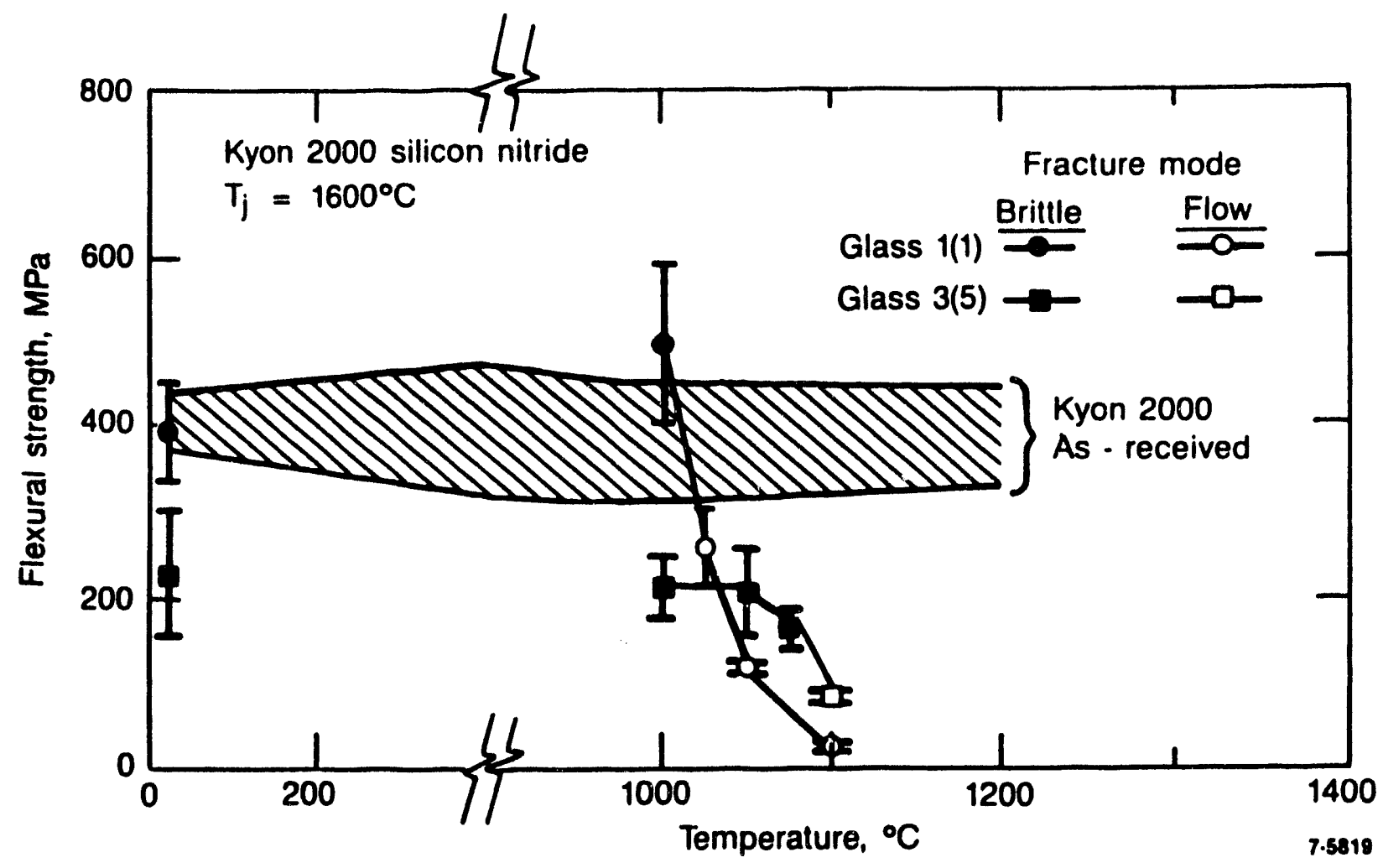

(a)

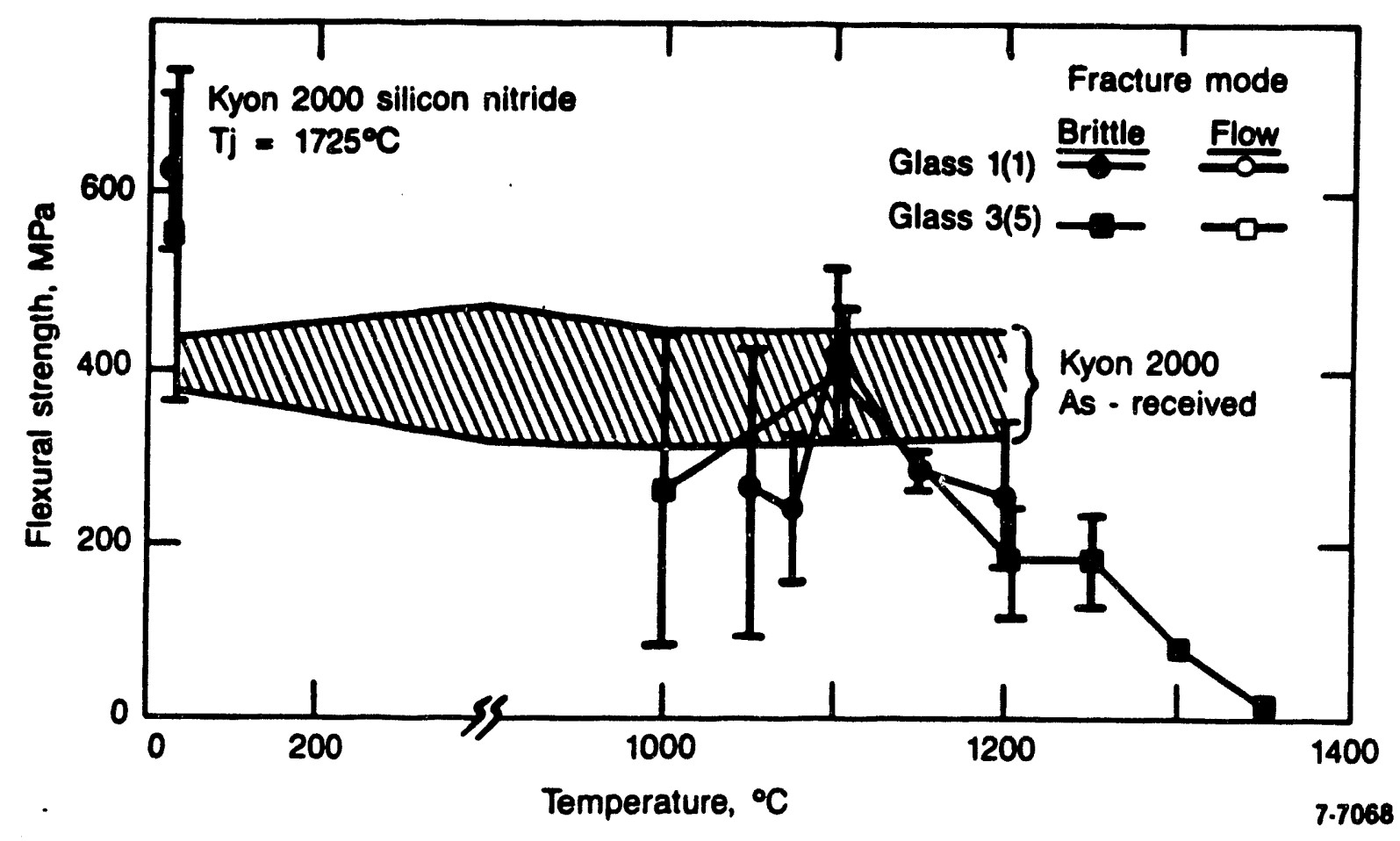

(b)

Figure 11. Flexural strengths of (a) glass-filled and (b) closed Kyon 2000 joints displayed as a function of temperature. The cross-hatched areas are the strengths of the unjoined original ceramics. 
temperature, viscous flow failure occurred. A comparison of the strengths of Ceralloy and Kyon joints is shown in Figure 12.

Pressureless joining produced joints comparable in strength to HIPped joints. In Figure 13, a comparison between HIPped and pressureless joined Kyon 2000 is shown. Due to the limited number of samples tested, error bars are not displayed for the pressureless joint data.

Interestingly, the transition from brittle to viscous failure behavior was apparently higher for the pressureless joints. Although not well understood, one possible cause of this behavior is the existence of less residual glass in the pressureless joints due to partial devitrification. It is considered possibly anomalous that the pressureless joints exhibited far superior room temperature strength.

Creep, devitrification, stress aided oxidation controlled slow crack, and viscous cavitation controlled slow crack growth were examined as possible controlling mechanisms for time-dependent failure of joints. Initially it was thought that creep failure would be limiting. However, no evidence of creep flow behavior was detected below $1000^{\circ} \mathrm{C}$. Instead, between 900 and $1000^{\circ} \mathrm{C}$ time dependent failure produced brittle-like (on the macroscopic scale) fracture surfaces more characteristic of slow crack growth. Devitrification of these joining glasses below $1000^{\circ} \mathrm{C}$ occurred much too slowly to govern time dependent failure. Silicon nitride ceramics containing a glassy grain boundary phases have been shown to exhibit slow crack growth above $1100^{\circ} \mathrm{C}[28]$. Since glass-filled joints resemble large glassy grain boundaries, it is reasonable to expect that slow crack growth could occur in joints.

Experimental observations indicated that both viscous deformation and oxidation of the joining glass occurred during slow crack growth testing. Based upon previous measurements of glass transition temperatures [29], it is known that the viscosity of oxynitride glass increases as nitrogen increases. Two possible kinetic control scenarios were considered. In one scenario, oxidation of the glass at the crack tip caused a lor $z$ al decrease in viscosity, in turn allowing viscous relaxation. If this were the case, oxidation would be the rate-controlling process. The second possibility was that viscous cavity formation and crack opening occurred first, allowing subsequent oxidation of the exposed surface. This process should be insensitive to oxidation rate and atmosphere, since viscous opening is temperature controlled.

On a macroscopic scale, fractured joint surfaces resemble brittle slow crack growth where no inelastic deformation is observed before failure. However, as shown in Figure 14, Figure 15, Figure 16, and Figure 17, SEM micrographs of the fracture surface show significant evidence of viscous deformation. Large cavities (10 to $20 \mu \mathrm{m}$ ) and ductile-like failure are evident near the original tensile edge of the sample. No brittle fracture markings are present in this area. Proceeding toward the compression edge, in the middle of the sample, smaller cavities and the first small fracture markings are observed. Near the original compressive edge, brittle fracture is evident, as shown in Figure 17. Fracture tails are seen pointing in the direction of crack propagation. Also near the middle of the micrograph in Figure 17, a vertical line is seen. This is a thermal expansion mismatch crack, which happens to coincide closely with the transition zone between mixed mode failure on the left and pure fast fracture on the right. These observations suggest that fast fracture occurred when the slowly growing crack achieved the critical flaw size. Although viscous deformation is strongly indicated by the fractographic evidence, it is not apparent whether deformation occurred prior to or as a result of oxidation. 


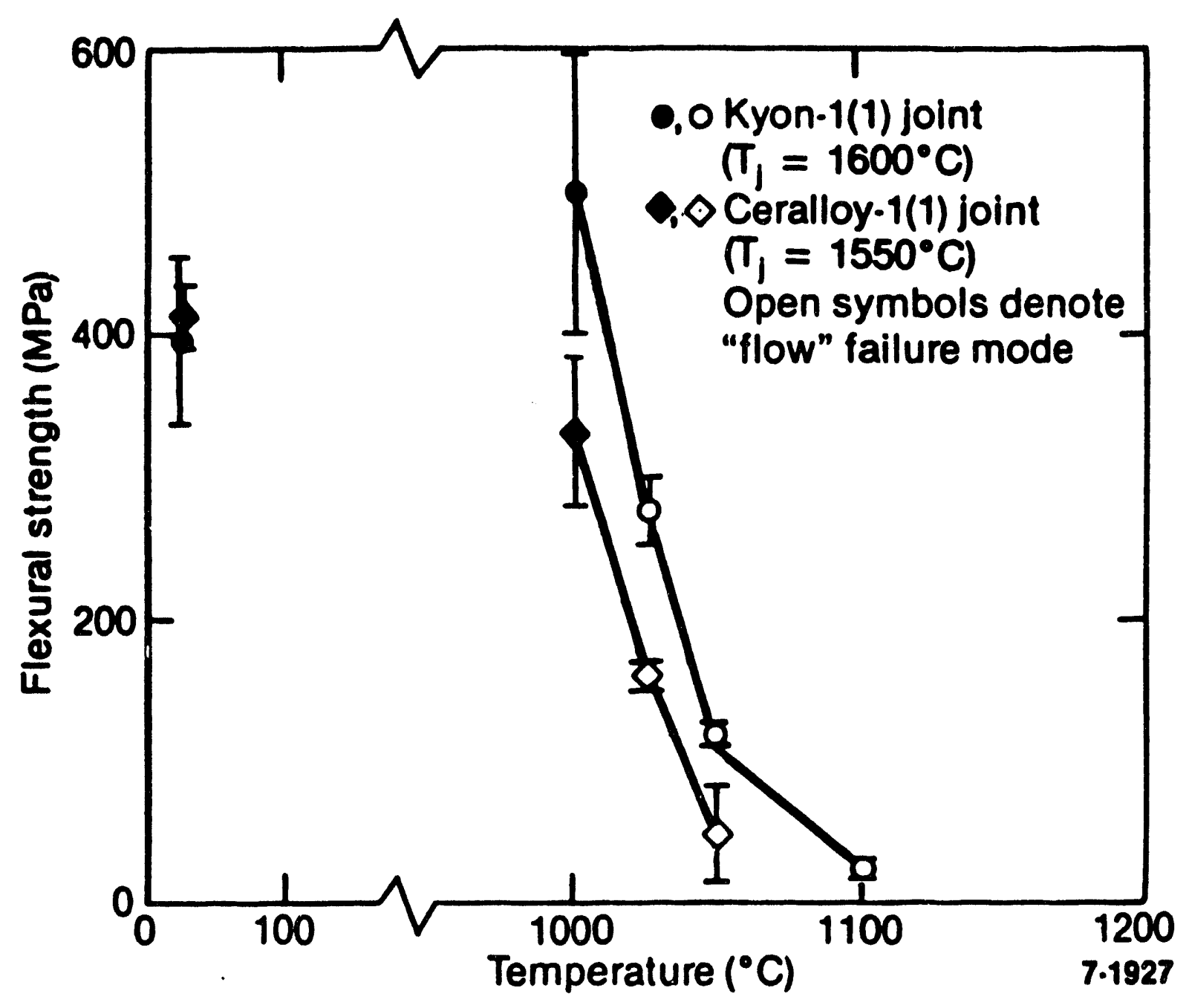

Figure 12. Ceralloy glass-filled joint strengths are compared with similar joints in Kyon silicon nitride. 


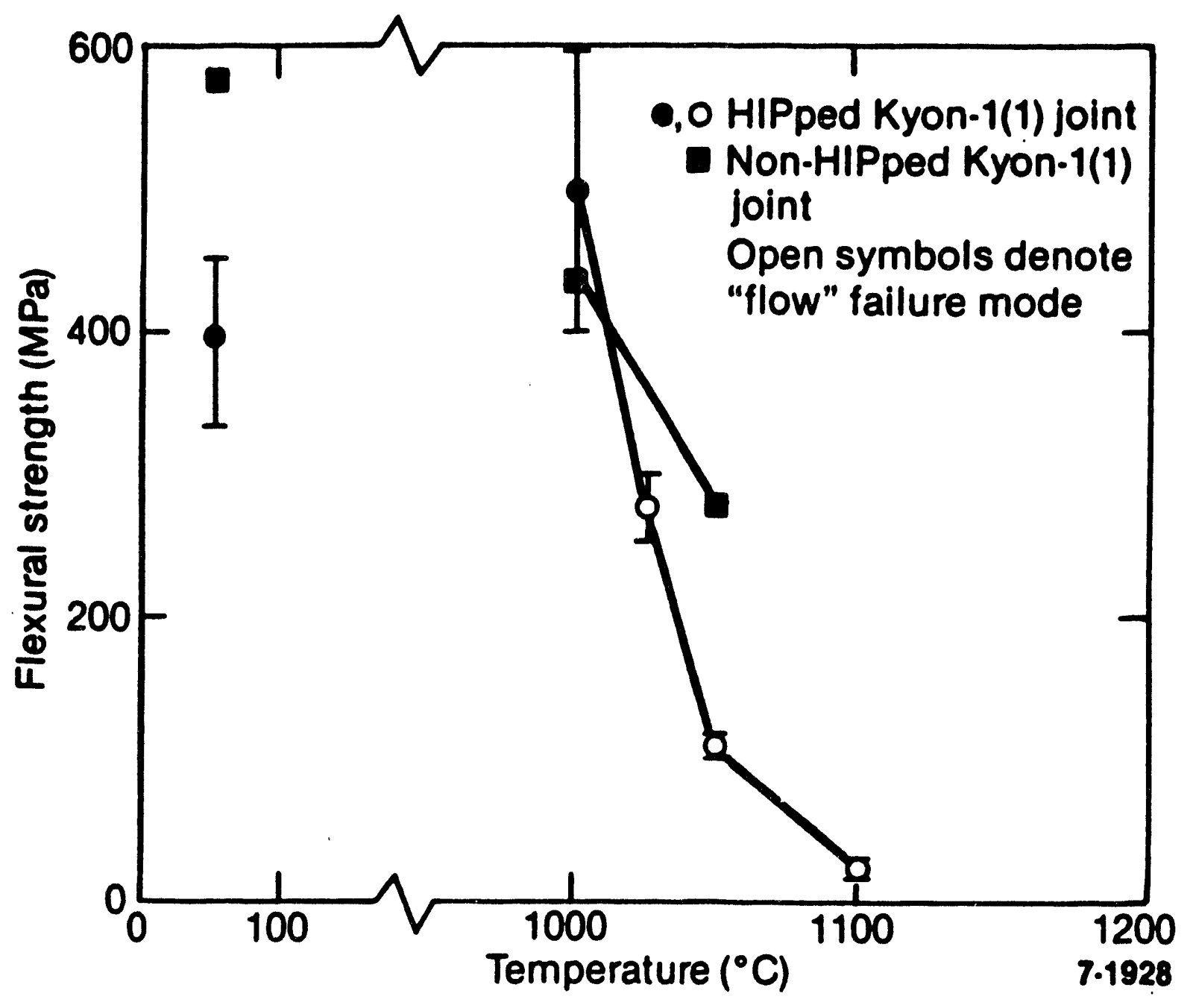

Figure 13. HIPped and pressureless joint strengths are shown for samples of identical compositions. 


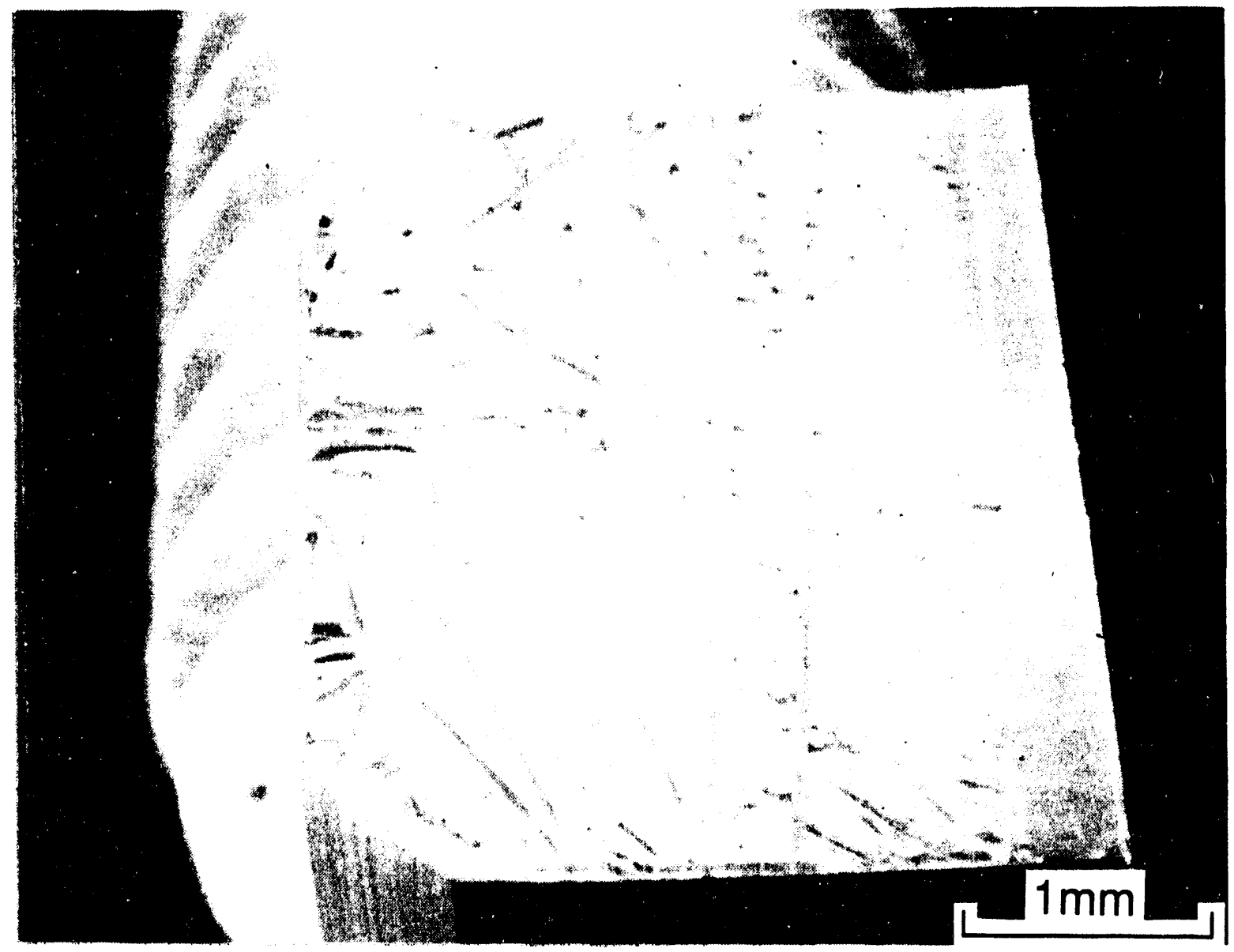

Figure 14. Micrograph of the entire joint fracture surface. The original tensile edge is on the left. 


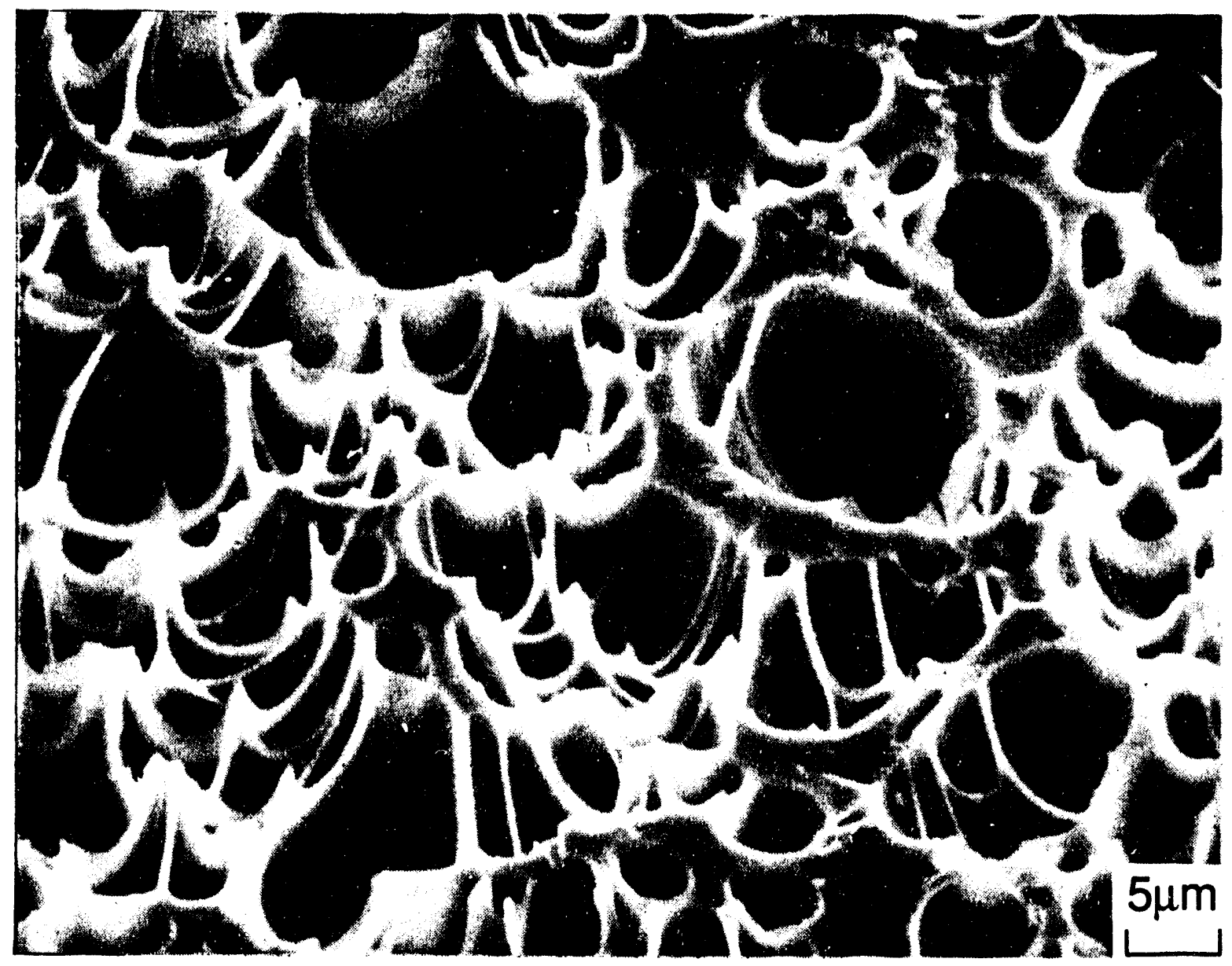

Figure 15. Micrograph showing high magnification near the tensile edge. 


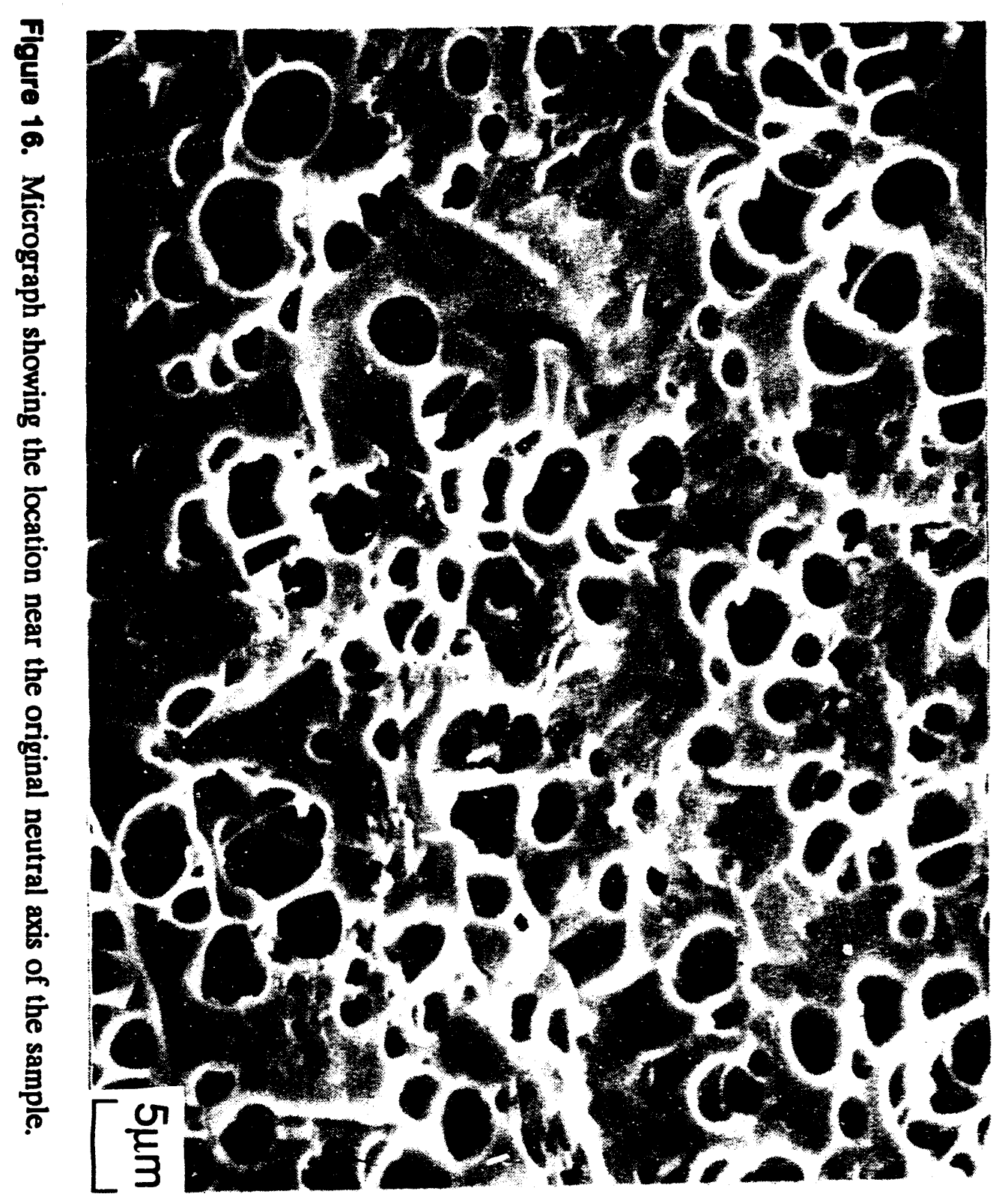




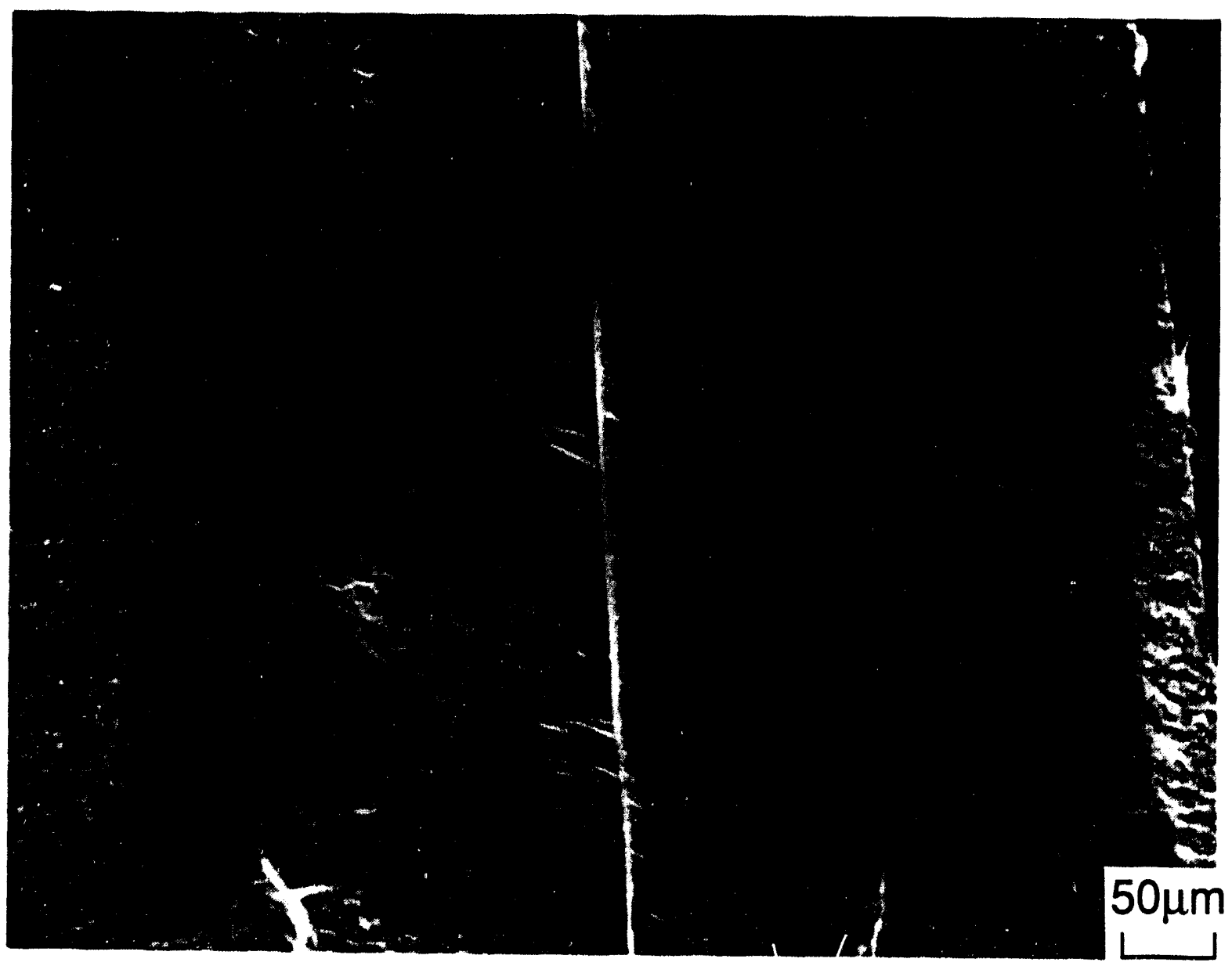

Figure 17. Micrograph showing the location near the original compressive surface. 
Auger electron spectroscopy indicated a significant difference in the extent of oxidation of the fracture surfaces under different atmospheres. In Figure 18 and Figure 19, atomic concentrations are displayed for two samples as a function sample depth. Both samples were mechanically tested at $991^{\circ} \mathrm{C}$ for approximately 35 minutes, one in dry air and the other in dry nitrogen. A pronounced difference was noted in the oxygen concentration curves. In the sample tested in nitrogen (Figure 18), the oxygen content decreased rapidly to the bulk glass composition. In contrast, the sample tested in air (Figure 19) was oxidized to a much greater depth. Because exposure times were similar, it was apparent that rates of oxidation were significantly different.

The rate of slow crack growth was independent of the testing atmosphere. SCG rate data are displayed in Figure 20, as the natural log of time-to-failure vs. temperature. Shown are the means of the several samples tested at each temperature and atmosphere. The standard deviations of data for each of the four atmospheric conditions were nearly identical at the same temperature. To improve clarity in Figure 20, only the wet air standard deviations are displayed. There is no apparent systematic change in slow crack growth rate with varying atmosphere. Since the Auger results have shown a significant change in oxidation rate with atmosphere, it can be concluded that slow crack growth in these samples was controlled by viscous relaxation.

A model of viscous cavitation nucleation and growth, developed by Tsai and Raj [14], provided an appropriate analog for this mechanical system. Raj and Dang found a solution for the growth rate of penny-shaped cavities in an adhesive layer between two rigid plates with the applied stress normal to the adhesive layer [30]. The resulting time to fracture equation was:

where

$$
t_{\alpha}=\frac{5 I^{2} \mu I}{\delta^{2}\left[\sigma_{n}+p\right]}
$$

$$
\begin{aligned}
& t_{\alpha}=\text { time to fracture } \\
& 1=\text { cavity spacing } \\
& \mu=\text { viscosity } \\
& \delta=\text { initial joint thickness } \\
& \sigma_{\mathrm{a}}=\text { normal stress } \\
& \mathrm{p}=\text { cavity relative pressure } \\
& I=\text { area integral }
\end{aligned}
$$

In this expression, stress $\left(\sigma_{n}\right)$ and cavity pressure $(p)$ were assumed constant with respect to time. During experimental verification of this quasi-steady state relationship, the cavity pressure was held constant by venting the array of cavities to the atmosphere. Reasonable agreement was found between this model and slow crack growth in oxynitride glass-filled silicon nitride joints [31], except for the joint thickness dependence. When the joint thickness was substantially greater than the cavity spacing, time-to-fracture was independent of the joint thickness [32]. 


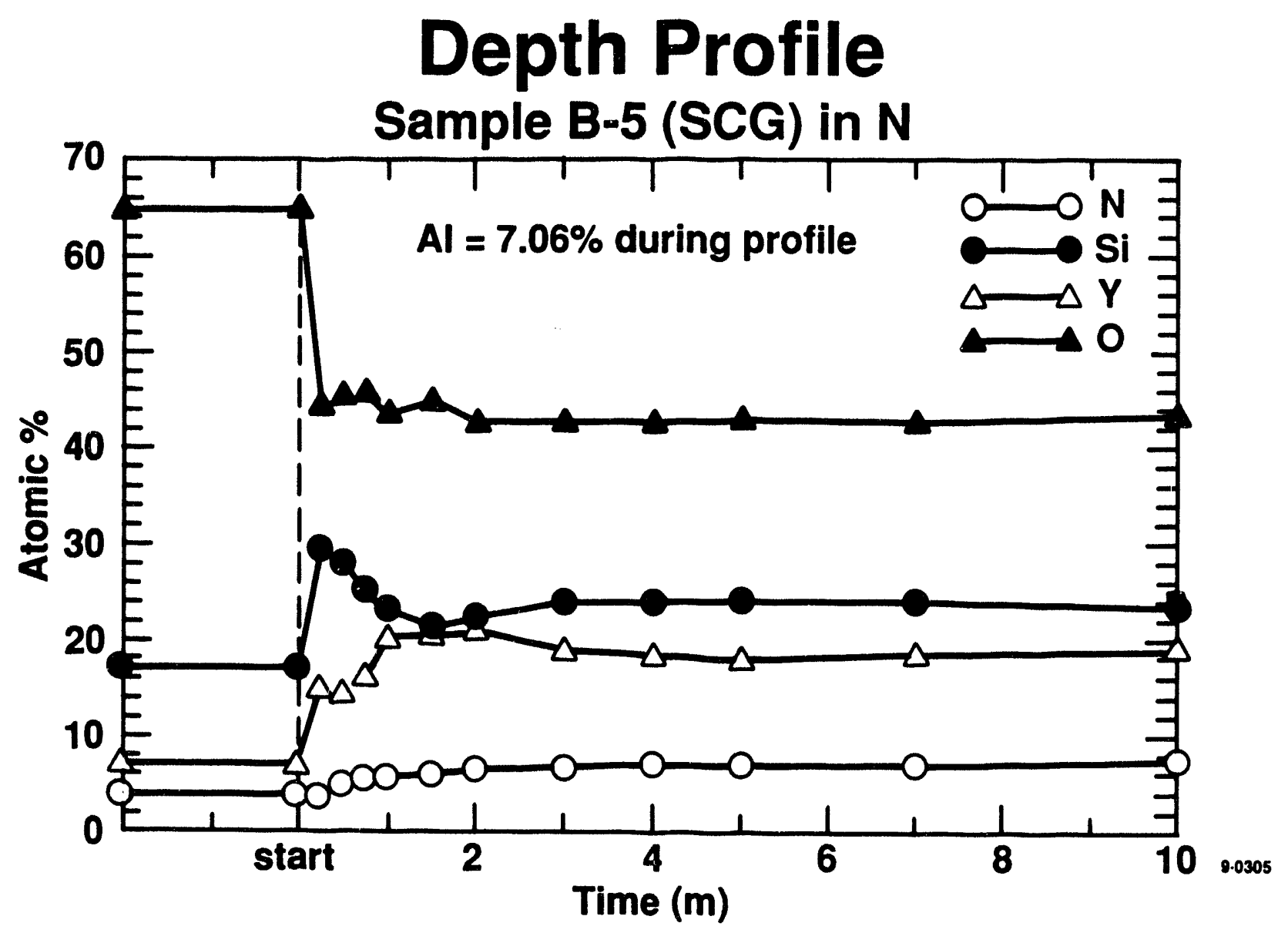

Figure 18. Auger electron spectroscopy of the fracture surface of a sample fractured in dry nitrogen. 


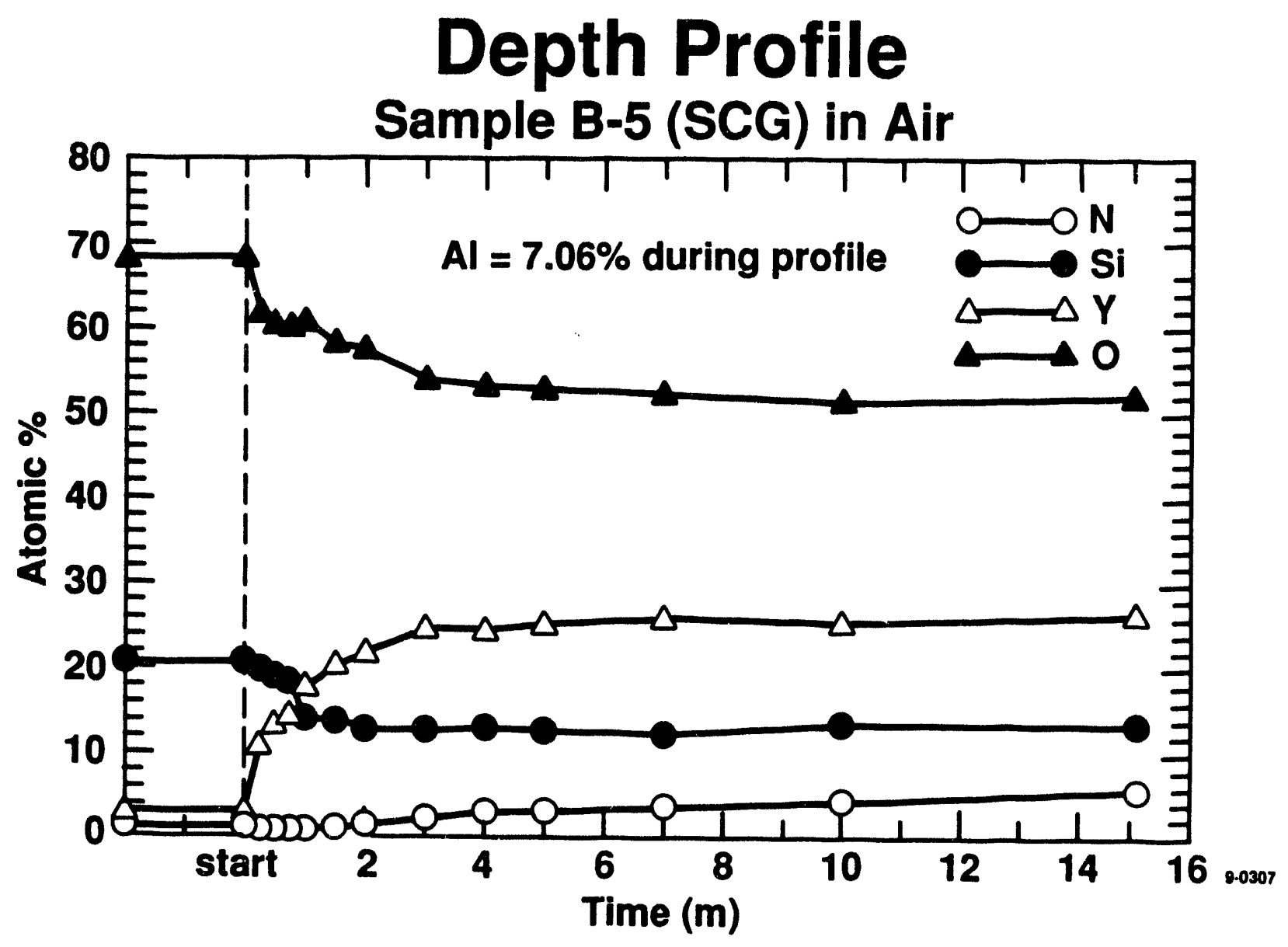

Figure 19. Auger electron spectroscopy of the fracture surface of a sample fractured in dry air. 


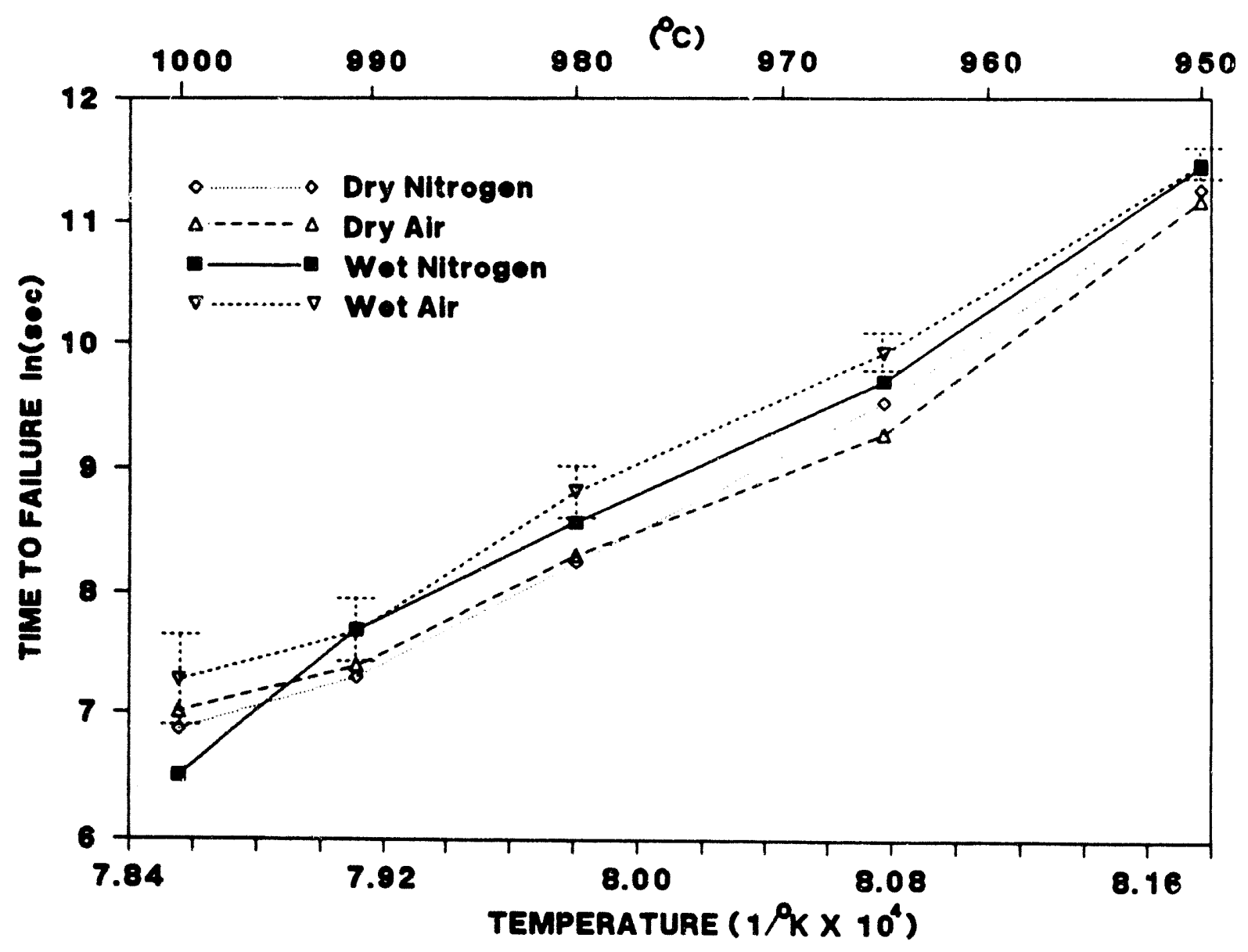

Figure 20. Slow crack growth time-to-failures are shown as a function of temperature for four different atmospheres. Only one set of standard deviation bars are shown for clarity. 


\section{SUMMARY}

During the INEL experiments, several commercial silicon nitrides were successfully joined using oxynitride glasses. Joining glass compositions were tailored to each silicon nitride. A sintered silicon nitride was joined by both closed and glass-filled joints. Glass-filled joints were successfully used on hot-pressed silicon nitrides.

Glass filled joints were comparable in fast fracture strength to the base ceramics up to approximately $1000^{\circ} \mathrm{C}$. Above that temperature, strengths decreased rapidly and viscous flow failure began.

Time dependent failure currently limits the service temperatures of glass-filled joints. Creep failure occurred in excess of $1000^{\circ} \mathrm{C}$. Between $900^{\circ}$ and $1000^{\circ} \mathrm{C}$, slow crack growth failure was observed.

Two mechanisms of slow crack growth were hypothesized: cavity nucleation and growth (viscous deformation), and stress aided oxidation. Fractographic evidence indicated that cavity formation and growth occurred between $900^{\circ}$ and $1000^{\circ} \mathrm{C}$. Auger electron spectroscopy verified that the oxidation rate of the joining glass was governed by the oxygen supply rate. The slow crack growth rate was independent of oxygen concentration. Reasonable agreement was found between the observed slow crack growth rates and those predicted using the Tsai-Raj viscous cavitation model. The study concluded that viscous relaxation and isolated cavity growth controlled the rate of slow crack growth in oxynitride glass-filled silicon nitride joints. 


\section{REFERENCES}

1. M. V. Goodyear and A. Ezis, "Joining of Turbine Engine Ceramics," Proceedings of the Fourth Army Materials Technology Conference (Boston, Mass. 1975) Advances in Joining Technology, Brookhill Publishing Co., 1976, p. 135.

2. T. Kaba, M. Shimada, and M. Koizumi, "Diffusional Reaction-Bonding of $\mathrm{Si}_{3} \mathrm{~N}_{4}$ Ceramics Under High Pressures," J. Am. Ceram. Soc. 66 [8], pp. C135-C136 (1983).

3. R. F. Pabst and G. Elssner, "Adherence Properties of Metal-to-Ceramic Joints," J. Mater. Sci. 15 , pp. $188-96$ (1980).

4. P. F. Becher and S. A. Halen, "Solid State Bonding of $\mathrm{Si}_{3} \mathrm{~N}_{4}$," Am. Ceram. Soc. Bull., 58, pp. 582-586, 1979.

5. A. Tsuge, "Effects of Various Additives on Sintering of Aluminum Nitride," NASA Tm-76650, February 1983, Translation of J. Ceram. Soc. Japan, 89, pp. 330-36 (1982).

6. M. Hoch and D. Ramakrishnan, "Condensation Coefficients of Refractory Materials, I. AIN and BN," J. Electrochem. Soc., 118, pp. 1204-11 (1971).

7. R. E. Loehman, "Transient Liquid Phase Bonding of Silicon Nitride Ceramics," Surfaces and Interfaces in Ceramic and Ceramic-Metal Systems, Materials Science Research, 14, New York: Plenum Press, 1981, pp. 701-711.

8. S. M. Johnson and D. J. Rowcliffe, "Mechanical Properties of Joined Silicon Nitride," J. Am. Ceram. Soc., 68 [9], pp. $468-72$ (1985).

9. K. H. Jack, "Review: Sialons and Related Nitrogen Ceramics," J. Mater. Sci., 11 [6], pp. 1135-58 (1976).

10. M. L. Mecartney, R. Sinclair, R. E. Loehman, "Silicon Nitride Joining," J. Am. Ceram. Soc., 68, [9], pp. $472-78$ (1985).

11. S. H. Knickerbocker, A. Zangvil, and S. D. Brown, "High Temperature Mechanical Properties and Microstructures for Hot-Pressed Silicon Nitrides with Amorphous and Crystalline Intergranular Phases," J. Am. Ceram. Soc., 68, [4], pp. C-99 - C-101 (1985).

12. R. E. Loehman, "Basic Research of Oxynitride Glasses," SRI International Report, AD/A-118 925, July 1982.

13. R. A. L. Drew, S. Hampshire and K. H. Jack, "Nitrogen Glasses and Glass Ceramics," Presented at the International Symposium on Ceramic Components for Heat Engines, Japan, October 1983. 
14. R. L. Tsai and R. Raj, "Creep Fracture in Ceramics Containing Small Amounts of a Liquid Phase," Acta Metall. [30], pp. 1043 to 1058 (1982).

15. K. D. McHenry and R. E. Tressler, "High-Temperature Dynamic Fatigue of Hot-Pressed and Sintered SiC," Am. Ceram. Soc. Bull. 59, 4, pp. 459-61 (1980).

16. C. H. Henager, Jr., and R. H. Jones, "Environmental Effects on Slow Crack Growth in Silicon Nitride," Presented at the 12th Annual Conference on Composites and Advanced Ceramics, Cocoa Beach, FL, January 1988.

17. J. L. Henshall, D. J. Rowcliffe, and J. W. Edington, "K $\mathrm{I}_{\mathrm{lc}}$ and Delayed Fracture Measurements on Hot-Pressed SiC," J. Am. Ceram. Soc. 62, 1-2, pp. 36-41 (1979).

18. H. C. Cao et al., "High-Temperature Stress Corrosion Cracking in Ceramics," J. Am. Ceram. Soc., 70, 4, pp. $257-64$ (1987).

19. B. J. Dalgleish, E. Slamovich, and A. G. Evans, "High-Temperature Failure of Ceramics," J. Mater. Energy Sys., 8, 2, pp. 211-225, (1986).

20. J. E. Siebels, "Oxidation and Strength of Silicon Nitride and Silicon Carbide," Ceramics for High-Performance Applications, III, Plenum Press, N.Y., pp. 793-804, (1979).

21. Phase Diagrams for Ceramists, $1-8$, compiled by the National Institute of Standards and Technology, and published by the American Ceramic Society, Inc., February 1990.

22. J. C. Mittl et al., "HIP Glassmaking for High Nitrogen Compositions in the Y-Si-Al-O-N System," J. Non-Cryst. Sol. 71, pp. $287-94$ (1985).

23. D. N. Coon, R. L. Tallman, and R. M. Nielson, Jr. "Hot Isostatically Pressed $\mathrm{Si}_{3} \mathrm{~N}_{4}-\mathrm{Si}_{3} \mathrm{~N}_{4}$ Joints Bonded with Oxynitride Glass," Adv. Ceram. Mater., 3, 2, pp. 154-58, (1988).

24. L. M. Barker, "Development of the Short Rod Method of Fracture Toughness Measurement," TR80-53 TerraTek, Inc., Salt Lake City, UT, July 1980.

25. D. R. Messier and A. Broz, "Microhardness and Elastic Moduli of Si-Y-Al-O-N Glasses," J. Am. Ceram. Soc., 65, 8, 1982, C-123.

26. A. Makishima et al., "Microhardness and Transparency of an La-Si-O-N Oxynitride Glass," $J$. Am. Ceram. Soc., 66, 3, 1983, pp. C-55-56.

27. D. N. Coon, T. E. Doyle, and J. R. Weidner, "Refractive Indices of Glasses in the Y-Al-Si-O-N System," J. Non-Cryst. Sol., 108, pp. 180-86 (1989).

28. G. D. Quinn and J. B. Quinn, "Slow Crack Growth in Hot-Pressed Silicon Nitride," Fracture Mechanics of Ceramics, 6, R. C. Bradt et al. (eds.), Plenum Press, N.Y., 1983, pp. 603-36. 
29. D. N. Coon, D. J. Landini, and E. Korda, "Thermal Stability of HIPped Y-Al-Si-O-N Glasses," submitted to J. of Non-Crystalline Solids.

30. R. Raj and C. H. Dang, "De-Adhesion by Growth of Penny-Shaped Bubbles in an Adhesive Layer," The Philo. Mag., 32, 5, pp. 909-22 (1975).

31. M. H. O'Brien and D. N. Coon, "Mechanistic Analysis of Slow Crack Growth Failure of Oxynitride Glass Joined Silicon Nitride," J. Am. Ceram. Soc., 74, 1, pp. 103-108 (1991).

32. M. H. O'Brien, "Cavitation Failure in Thick Adhesive Layers with Abundant Cavity Nucleation Sites," submitted to the J. Am. Ceram. Soc. 


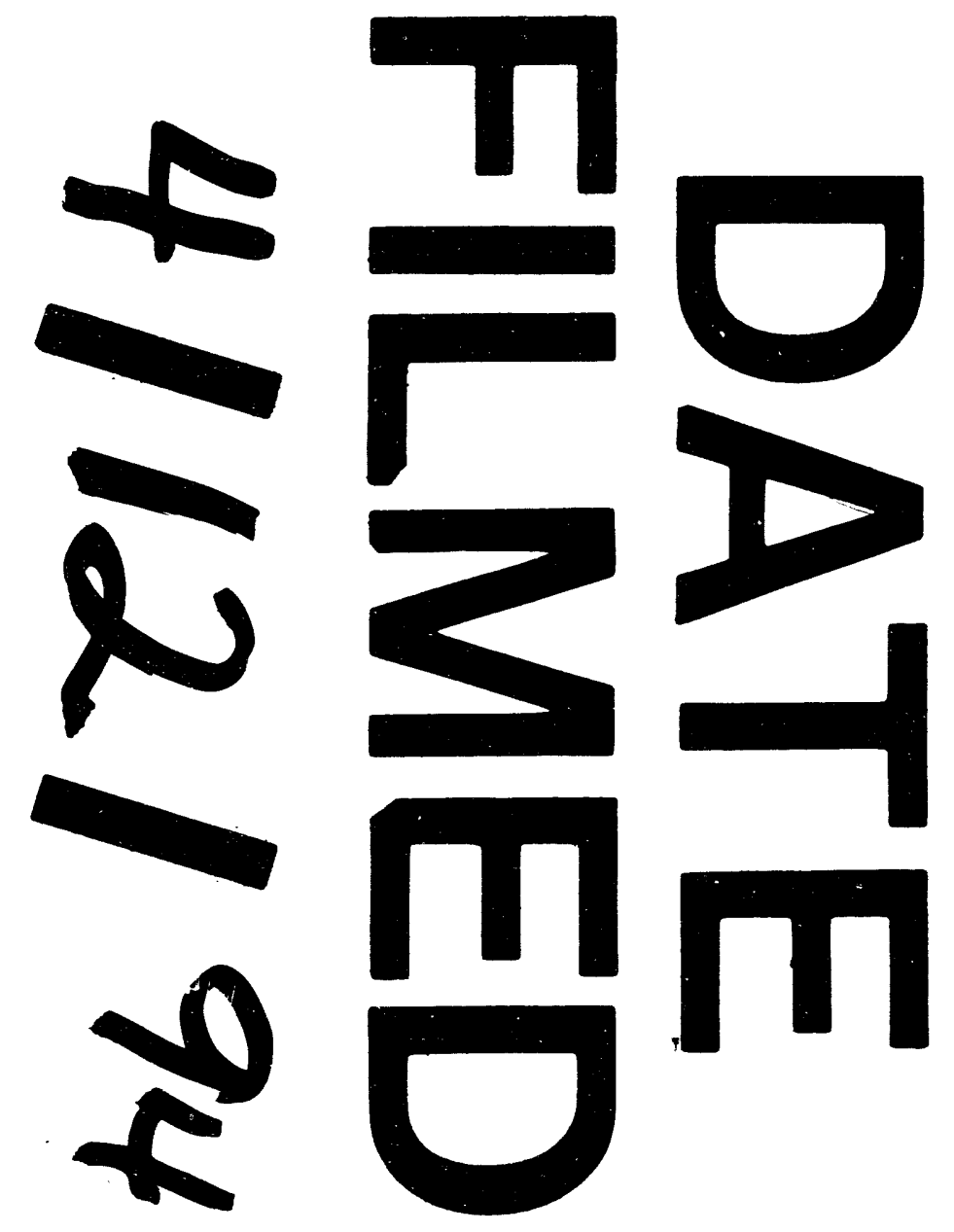


